$$
\begin{aligned}
& 5 F \\
& 487 \\
& J 6
\end{aligned}
$$




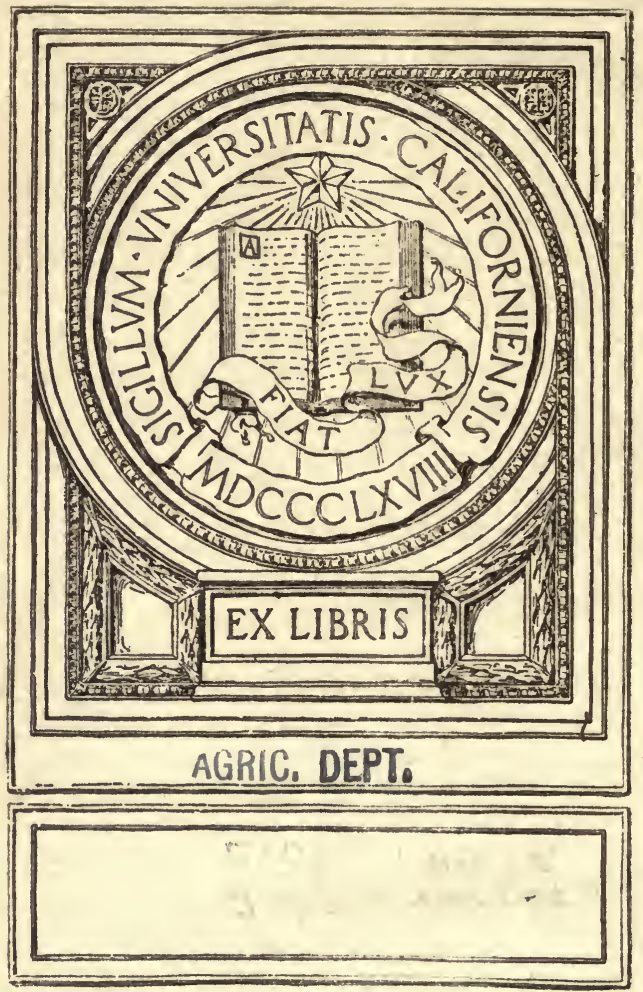




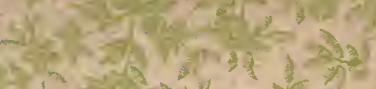

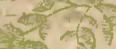 \\ $-7.72$ \\ C 3 (N}

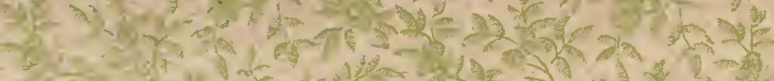

(5)

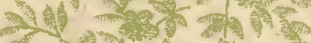

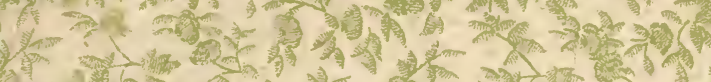

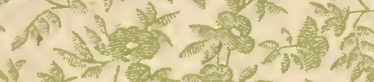

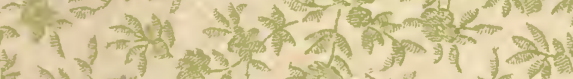

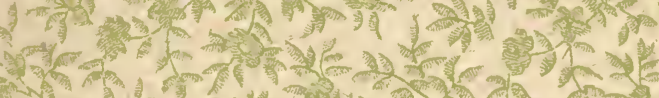
然

(1) हो हो

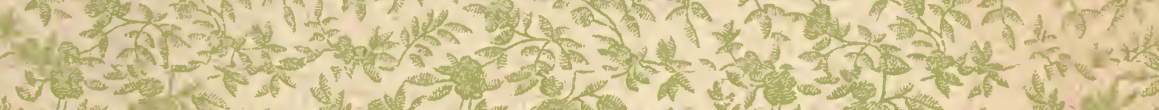

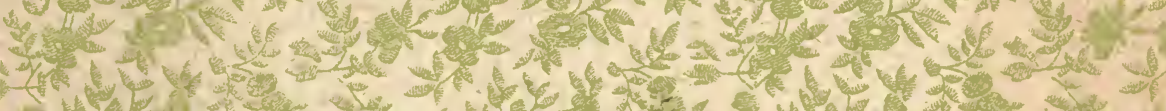

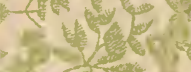
$x^{2}-\frac{1}{2}$ 1) 2 les 7fer 46 203 of

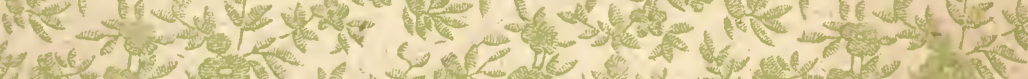
(15)

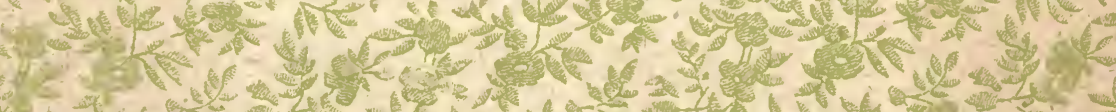
(2)

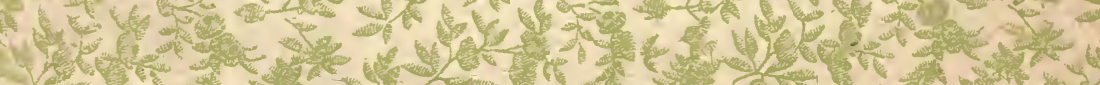
6. (1) 60 (1)

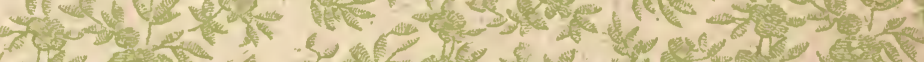
Ly" 2. 36) 

bampliments of Thirs D. C. fohmson 




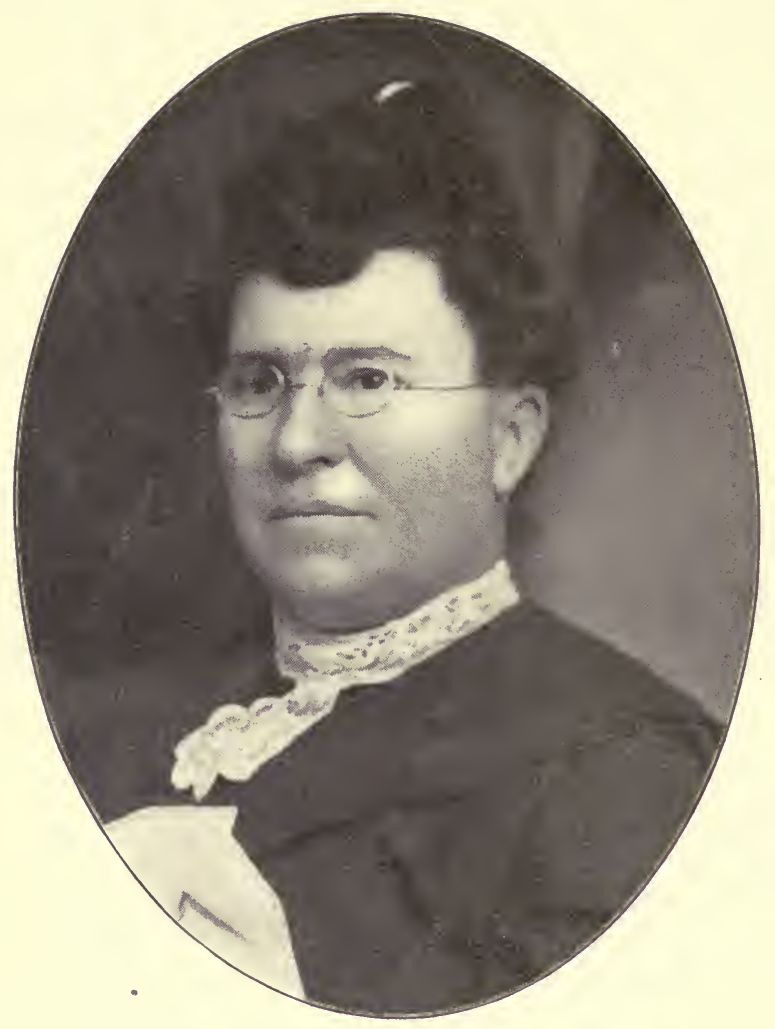

Mrs. Rebecca Johnson 


\title{
HATCH, BROOD, FEED AND
}

\section{PREVENT CHICKS}

\author{
FROM \\ DY I NG I N THE SHELL
}

BY

MRS. REBECCA JOHNSON

MAXWELL, IOWA

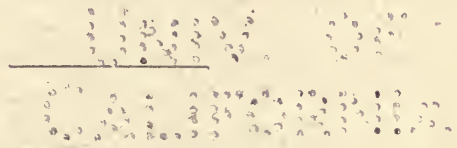

[REVISED SECOND EdiTION]

The L. R. Shepherd Publishing Co. MAXWELL, IOWA 
CoPyrighted 1905

COPYRIGHTED 1906

BX

MrS. ReBecca JoHnSON

Maxwell, lowa

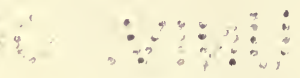

40 


\section{INTRODUCTORY}

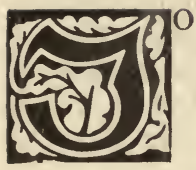

THE READER: I will tell you how I came to write this book. In the year 1882 I took up poultry raising as a money making proposition, believing there was more money to be made for the capital invested than in any other line of business and am still of the same belief, but I became dissatisfied with the slow way of raising chickens with hens. I had read that chicks could be hatched by artificial incubation, but I had never seen an incubator, and knew nothing of the natural laws of incubation, but if one wants to learn they must investigate, so I went to work. I placed a thermometer under a setting hen every day for three weeks and found first the temperature at which she kept her eggs each day during the whole hatch. The hen from which I was taking lessons I set on the porch near the window, where I was doing my spring sewing. I watched her closely that I might know how many times she turned her eggs during the day. She turned them about every four hours. I did the same for a while, but soon found it was not necessary. After I had found the proper temperature at which to keep the eggs during incubation, and also how often to turn them, I commenced the construction of an incubator. I used two dry goods boxes, one of which had served me as a wood box for several years. One box was a little larger than the other. I placed the smaller one inside the larger, and filled the space with sawdust. I thought it had to be thick so it would retain the heat. That was not a bad idea, either. I made a hot air space at the top and bottom. I thought the eggs should have heat from above and below. Then I put pipes through it and heated it with lamps just about the same as the modern hot air machines are heated today. It was a rude concern but it hatched chicks just the same. After the thermometer registered 102 degrees, I placed the eggs in my new machine and kept the temperature at the same point each day for three weeks, just the same as the hen did, with the result that I hatched 108 chicks from 116 eggs. I did not test any out. I did not know enough about such affairs at that time. I had six ventilators in the top and six in the bottom. After awhile I saw where I could make an improvement in my machine. I went to work and made a new one, and then another, and so on until I had made nine. Each machine was an improvement over the other. I made my own brooder also. Here is where goods boxes played an important part again. I put sheet iron in for a floor and placed a lamp under it to keep the chicks warm. Now with my home-made incubators and brooders I have raised as many as twenty-six hundred chicks in one year, and seldom less than fifteen hundred. 
Well, my success got into the papers. Sometimes good things were printed as well as bad things. Then I began to receive letters of inquiry in regard to operating an incubator, how and what to feed brooder chicks, and everything pertaining to poultry culture. The first few years I did not receive so many letters, but as the use of incubators became more prevalent, there were more inquiries. I tried to answer every one, for how glad I would have been twenty-two years ago to have received a letter from some one who had had twenty-two years of practical experience, and how it would have helped me through many trying difficulties and saved me many disappointments. At last I received so many letters that it was impossible to answer them all and do my work as it should be done. One day a friend said to $m e$, "Why not write a book on incubation and raising brooder chicks, telling everything in detail, jụst as you know it from experience; it would be so helpful to new beginners?" This was the first time I had ever thought of the matter in that light. I wrote to several in answer to inquiries, that I would write a book if I thought I could sell enough copies to justify me. Mr. Payne, editor of the Nevada Representative, published one of those letters. Then I began to receive orders four months before I had commenced to write, so I thought I would put my experience to good account. Hence this book. Hoping that this little volume will prove of pleasure and profit to the reader, I remain

Most sincerely yours,

The Author. 


\section{How to Hatch, Brood, Feed and Pre= vent Chicks From Dying in the Shell}

\section{Saving Eggs for Incubation}

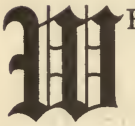

HILE you are saving eggs to fill the incubator, keep them in a moderately cool place, not lower than sixty degrees temperature. They should not be kept in a room where there is a fire, unless the weather is quite cool, until about eight or ten hours before you place them in the incubator. Then they should be brought into a room that has a fire in it, for eggs when kept in a cool place will sweat when they come in contact with the heat, and it is better for them to go through that sweating process out of the incubator than in it, for it takes so much longer to get the eggs to the proper heat for incubation if they are allowed to sweat in the machine. Do not keep them in a cellar or cave if they are the least bit damp. I find that a bedroom is about the best place to keep them. Turn your eggs once a day after the third day. Be sure that your hands are free from grease while handling them. Put a clean cloth or paper in the basket or box before placing the eggs in it. You cannot be too careful in this respect, for sometimes the least speck of grease will kill the germ of the egg. It is best not to keep your eggs in an egg case while saving to set. Eggs should not be kept longer than two weeks, although I have kept them three weeks, but the best results are obtained from eggs not over a week or ten days old. When this is done a larger per cent will hatch, and there will not be so many crippled chicks if you set fresh laid eggs. You will get more pullets from medium sized eggs than you will from very large ones. Very large pointed eggs, if they hatch at all, produce almost invariably males. You, perhaps, have noticed this. Leghorn eggs hatch better than the larger breeds, such as Plymouth Rock, Wyandotte, Buff Cochin or Brahma. Leghorn eggs have a very thin shell, consequently they are easier to pip. Do not save eggs from inbred fowls to set, if you can possibly help it. You must procure eggs from well-bred, healthy fowls to make success sure. Better pay a few cents more per dozen and start right. Chicks hatched from eggs of inbred fowls are more liable to disease than those hatched from pure-bred fowls. I have seen 
good results from mongrel hens and good blooded cockerels. But if you are going into the business for profit get a good incubator and a good brooder, then buy or exchange eggs with some one that has good blooded fowls, and start right. It will cost a little more at first, but will pay you big dividends in the end. If you have eggs shipped to you, or if you carry them in a buggy any distance, they should rest at least ten hours before placing them in the incubator. If you have good blooded fowls you can sell your eggs and cockerels at a good price, too, just as well as your neighbor. Not only this, but you will get better returns for your labor, for it costs just as much to raise poor fowls as it does good ones; yes more, for pure breeds are stronger and more likely to live.

\section{Testing the Eggs to Set}

T ALWAYS test the eggs before I place them in the machine, especially if $I$ buy them. One then has a chance to fill their machine full of good eggs. Some eggs have very thin, spotted shells. The shell will look very thin in some places and thick in others. These you should not set. Others that look as though they had been set on awhile should be discarded also. Do not set eggs that have bulged places on them; they almost invariably make cripples, nor any eggs that are too long or too round. Avoid extremes. Set only medium sized, nice, smooth, uniform eggs, not too large or too small. The room whére you are testing the eggs should be dark. Night is the proper time to test, but if you want to test in the day time, darken the windows with something heavy so as not to admit any light whatever in the room.

\section{Testing Eggs for Fertility}

T TEST my eggs for fertility on the evening of the seventh day. Do not 1 test in a very cold room. If you think they will get too cold before you finish testing, carry them to a warmer room to do the work. Take out one tray at a time and close the machine, turn the lamp up a little so the egg chamber will be quite warm, when you return the eggs, and it will not take them so long to get back to their proper temperature.

Do not cool or turn the eggs the evening you test them. You can turn each egg as you place them back in the tray after you have tested them, and they will get cool enough in the operation of testing. As soon as you finish testing the first tray return it to the machine at once, then test the other one. Very dark brown eggs are harder to test than light colored ones, consequently I test them again on the sixteenth day. Then you can 
remove all that is not fertile. You can keep a more even temperature if all the infertile eggs and those that have dead chicks in are removed. Eggs that have a live chick in them are as black as night on the sixteenth day. Those that have dark and light spots in them are eggs that have started, then died, the death being caused by too high a temperature some time during the hatch, or perhaps a weak germ that would not have lived had it come to maturity. These eggs should all be removed. It is more difficult to keep the proper temperature in the egg chamber if there are many bad eggs in your machine. Do not hold the eggs too close to the lamp while testing, as you will injure them. You will find eggs which you are doubtful about. These you should mark and in a few days examine them again. If you smell a foul odor in your machine hunt till you find the bad eggs. The quicker they are removed the better, for a spoiled egg may injure the hatch. Some Incubator Companies will tell you to test your eggs three times. This is unnecessary. Twice is sufficient. When $I$ have a great deal to do I sometimes get mine tested but once, but it is better to test twice. You will get better results if all eggs with dead chicks in are removed.

Never add eggs at different times. Put them all in at once. If you haven't enough to fill your machine wait a few days, for it will take more oil to hatch a few than an incubator full. The more eggs you have in the machine, the more animal heat you will have, consequently it will take less oil. The more fertile eggs you have in your incubator, the easier to keep the desired temperature.

\section{How to Start Your Incubators}

$S^{\mathrm{n}}$ ET up your incubator according to the directions you receive with it. Place incubator in a bedroom or dry cellar; it should not be in a room where there is a fire unless the fire is kept up all the time. It should be in a room or cellar where the thermometer will not register lower than fifty degrees, and where the temperature can be kept as even as possible. Never try to operate an incubator in an out-building in freezing weather. It would be all right in summer time if there was no draught and it could be well ventilated and kept dry, but the better the room is adapted to this purpose the less attention the incubator demands and the better the results will be.

If your machine is a hot water one it must sit perfectly level in order to get the proper circulation through the heating pipes. It should not be set by guess, but you should use a spirit level. Now put on your regulator according to directions. Fill your boiler or pipes with boiling water. It would take too long to heat up the egg chambers if cold water was used. 
Light the lamp and run the machine until you have perfect control of the regulator, so that the thermometer will stand at 102 degrees for several hours before placing the eggs in the incubator. If your machine is a hot air machine it doesn't matter so much about its being level, but other conditions must be the same as a hot water machine. You should use the best oil you can procure. If you get cheap oil your wicks gum and the burners will clog up and ofttimes an explosion will result. I have lost my entire hatch several times by using poor oil. The lamps would blaze up and my eggs get too hot before I knew it and the chicks would all be dead in the shell.

\section{Proper Temperature for Successful Incubation}

Y OUR thermometer should register 102 degrees for several hours before you place your eggs in the incubator. See that your regulator works perfectly according to the directions that came with your ma-

chine. I cannot tell you just how it should be, for there are so many different kinds, but each machine has instructions which you should go by to the letter in setting up your machine. After placing the eggs in the incubator turn your lamp up a little so that it will not take so long to get your eggs to the proper temperature for incubation. When your thermometer registers 102, if it has a tendency to run higher, turn down the blaze of your lamp until it will stay at 102 . Keep a steady heat of 102 the first week. If it runs to 103 the last of the first week, no harm results; the second week keep the temperature at 103; the third week keep the temperature at 103 and 104. Do not let it run higher than 104 if you can help it. At pipping time keep the temperature at 103 and 104. This is the critical time. Too high a temperature and not enough ventilation is the cause of chicks dying in the shell. Your eggs are at least two degrees hotter at pipping than your thermometer registers because of so much animal heat in the eggs and the exertions the chicks make to free themselves of the shell. This is the reason I advise a temperature of 103 degrees. and not to exceed 104 . You will hatch a greater per cent with the temperature at 103 than a higher temperature. As the hatch progresses remove the shells and turn all the eggs with the pipped side up. They will ofttimes smother when the pipped side is against the wire.

Do not be afraid to open your machine so long as you keep your temperature up to 103 and 104. Do not disturb it until the chicks begin to come out of the shell. If you do not remove the shells, they will sometimes slip over an egg that is pipped and smother the chick. If your machine has not more than one or two ventilators, go to your machine every half hour and fan the door back and forth two or three times and fill the 
egg chambers with fresh air, or in other words, oxygen. The egg chambers must have fresh air while your eggs are hatching or your chick will die in the shell. I know that most of the instruction books say not to open your incubator till the hatch is done. This is a grand mistake and you will find it so if you will only investigate. There was not room enough in the nursery of my incubator to hold all the chicks I would hatch at one time. My incubator has nine ventilators, and then the chicks would open their mouths and pant; I would have to remove them as fast as they became strong enough. Too high a temperature at the beginning of the hatch injures the embryo; that is why some eggs start, then die after a few days of incubation. If the proper temperature has been maintained and some die after a few days, those are eggs with weak germs and are doomed, whether they die the first week or after incubation.

\section{Turning and Cooling the Egg}

W HEN placing the eggs in the incubator care should be taken to turn each egg over, as you do not turn them again for twenty-four hours. At the end of twenty-four hours turn them and change the outside eggs to the center and the center eggs to the outside. You will have a more even hatch by changing them in this way about every four days during the hatch. Do not cool the eggs the first time you turn them, only as long as it takes to turn and change them from the outside to center. But after this, cool them once and turn them twice a day, each day until the eggs begin to pip; then do not cool or turn them any more. Always cool your egge in the morning; never in the evening, only as long as it takes to turn them. When you cool them in the morning do not turn them till they are cold, and just before you replace the trays in the egg chamber. This is nature's way. If you will observe a hen you will find that she seldom cools her eggs more than once a day, and that early in the morning, and if you will examine the eggs you will find they are perfectly cold. I used to advise cooling eggs twice a day, but found by experimenting that I obtained better results by cooling but once, unless the temperature runs too high during the day. Then take the trays out of the incubator for a few minutes, so as to run the temperature down quickly. Avoid extreme heat if possible. There is no given length of time to cool the eggs; that depends on the temperature of the room in which the incubator is located, and will have to be governed entirely by the operator. Just leave them out of the incubator till they feel not cool but cold to your face. There need be no fears that this cooling will do harm; the chicks will be the stronger for it and a larger per cent will hatch. In May, June and July, it takes longer for the eggs to cool than it does in March and April, 
and as the hatch advances you will observe there is more animal heat in the eggs, consequently it will take longer to cool them than it did in the first of the hatch. If you want strong, healthy chicks, get them used to the cold while in the shell. They can stand more cold without injury while in the shell than they can after they are hatched, and it is better for them to get used to the changes of temperature while in the embryo state than to wait until after they are hatched. If you keep a high temperature during incubation, with little or no cooling, then place your chicks in a brooder with the temperature twenty degrees below that of your incubators; the change is too great, and your chicks will contract disease at once, and you will lose half or two-thirds of them. This sudden change is of ten the cause of bowel trouble and pneumonia in brooder chicks. I have left the trays out of my incubator all night several times after the eggs had been under the process of incubation two weeks. The first time I did this it was a mistake. I had forgotten them, and I thought of course my eggs were ruined, but they hatched just as good as those in the rest of my incubators, and the chicks seemed stronger, but the hatch was retarded one-half day. I have left them out purposely since that time, just to experiment, and learned that eggs will stand all sorts of cold. just so it is not freezing weather. If you will take lessons from your hens you will learn just how cool your eggs should be and it will be a wonderful help to you.

If you will always turn the eggs one way you will have less cripples. What I mean is, do not turn them backward one time and forward the next. Remove the first egg from each row, which will allow the egge to move forward. Now with your hand move them forward gently. You will note that the eggs are turned about half over. Next place the eggs you have removed in the vacant space in the rear of the tray. This. also changes their location in the incubator at each time of turning. For instance, after you have turned the eggs to the number of times you have eggs in each row you will then have the eggs that were first placed in the rear end of the tray back again to the front end of the tray. If you will always turn them toward the little opening where the chicks drop into the nursery you cannot make a mistake. I would advise the operator to shift the trays from end to end and from side to side in their machine every time they turn the eggs, providing their machine has two trays. If they are operating a small incubator with but one tray, then all that is necessary is to turn the tray end for end. You will find this is quite a help in operating and will overcome difficulties that are bound to exist where you set so many eggs together. You will avoid a lingering hatch by following the rules given above. 


\section{Ventilation and How to Prevent Chicks From Dying in the Shell}

THERE are many kinds and makes of incubators. Some are made of good material but do not give satisfaction because they are not ventilated properly. Others are made of poor material and soon warp, or the tank will rust out. Some do not give a uniform heat throughout the egg chambers, which makes a lingering hatch. Now I will tell you how an incubator should be ventilated for best results. There should be four ventilators in the bottom, one at each end, about six inches from the end and on a line with the center of the incubator, and one at each side, (I mean the front and back,) about six inches from the front and back and on a line with the center the other way of the incubator. These ventilators should be about one-half inch holes and a strip of tin bent and tacked over them so that the cold air will not come in contact with the eggs. Then there should be two holes the same size as the others in each end just below the tank and about six inches from the front and back of the machine. There should be no ventilators in the front or back of your machine, only in the ends, bottom and top. The ventilators in the ends should be above the eggs so there will not be a direct draught over them. There should be a two-inch hole in the top of the machine, about the center. This ventilator I use when my chicks are hatching. I open all nine ventilators after the eggs begin to pip. This gives the chicks plenty of fresh air, and fresh air contains oxygen, which is the life of every living creature. Not a living thing that breathes on the face of the earth could live without oxygen. Then do you wonder that your chicks die in the shell, shut up in a tight box with a temperature of 103 or 104, with little or no fresh air. And your directions will tell you not to open the door until your hatch is done! Dear reader, just reason a little and you will see that this is all a grand mistake. Your chicks must have fresh air and if your machine hasn't the proper ventilation just go to it every little while and fan the door back and forth three or four times. This is necessary only at hatching time. Chicks must have air, so do not fail to give it to them. I never allow my chicks to pant in the incubator. I have taken the tray out and set it upon the machine for a minute to give my chicks fresh air, for if they get over-heated in the incubator it is just as fatal to them as if they were overheated in the brooder. Too high a temperature and not enough ventilation at hatching time will cause chicks to have bowel trouble.

The ventilators on the end of the machine should have a round piece of tin tacked over them so they can be moved to give fresh air when it is necessary. I open these end ventilators one-third on the third day of in- 
cubation. At the end of the first week I open them a little more, and every day or two I open a little more until at the end of the second week they are wide open-except the one on top-and continue so until the end of the hatch. The two inch ventilator on top I begin to open at pipping time, just a little at first and more as $I$ see it is necessary. Incubators that haven't enough ventilation can be reconstructed by putting in extra ventilators and made to do good work. The four ventilators in the bottom of the incubator should be left open all the time with a piece of cupped tin over them. This piece of tin should be about four inches long and three inches wide and cupped just a little so the air can enter the egg chamber. This tin gives the air a chance to get warm before it reaches the eggs. I have hatched chicks by the thousand according to the directions I have marked out to you, and so can you if you will do just as I have told you.

\section{Moisture and When to Introduce It}

A FEW days before your incubator is due to hatch, take a piece of A loosely woven burlap or coffee sack, wash it perfectly clean and scald. After it dries press it and cut it just the size of the bottom of your incubator. Hem it all around so the little chicks will not tangle in the ravelings. Now if you have any ventilators in the bottom of your machine (which you should have), make a hole in the burlap just over the ventilators and buttonhole around it, so that the air can pass through into the egg chamber, just the same as if the burlap was not there. As soon as you see four or five eggs pipped remove the trays from the incubator and place them on a blanket, then take some luke-warm water and sprinkle your eggs and replace the trays at once Your thermometer should register 104 degrees before you give your eggs this bath or sprinkling, for this sprinkling will have a tendency to lower the temperature a little. Do not let your thermometer register more than 104, or below 102. At pipping time, after the chicks begin to come out of the shell, dampen burlap mentioned above with boiling water. Do not make it wet enough to drip. Now remove the trays again. Place the steaming burlap in the bottom of your incubator. Now replace your trays while the burlap is steaming, close your doors, and do not open again for awhile so the eggs will get the full benefit of the steam. Leave this burlap in the bottom of your machine till the hatch is done. This is all the moisture you need to introduce into your machine during the whole hatch unless for some cause the temperature in your incubator should run up to 108 or 110 or higher. You can sometimes save your hatch, or a part of it, if they have not been hot too long, by removing the trays from your machine and shower the eggs with warm 
water. Leave them out of your incubator until the eggs are cool. Once I saved 167 chicks from 208 eggs, after my thermometer registered $113 \mathrm{de}$ grees, by showering them in this way. I turned the flame of my lamp up and forgot it, as we all do sometimes, you know. 'Do not let this occur very often for they will take up a great deal of moisture when they are quite warm. This sprinkling is to lower the temperature quickly. If they were left to cool of themselves after the thermometer registers 113 , not many would survive without this bath. I used to moisten my eggs every day. The consequence was I drowned my chicks or a great many of them. I have learned by experience that the eggs need drying out instead of moisture, so the chick will have room to pip.

You will observe during the last few days of incubation that your trays are much lighter than they were the first week of incubation. Sometimes chicks have a tendency to stick to the shell. This is why you should put this steaming burlap in the bottom of your incubator. It penetrates the egg at once, loosens the chick so it can turn and pip the shell clear around and come out. The pans which the Incubator Companies furnish with their incubators are a perfect nuisance. They moisten a few eggs, that's true, but only those that are just above the pan. For best results and an even hatch you want your eggs all moistened at the same time. If you would have success do not fail to do as I have told you in every detail. This damp burlap may have a tendency to lower the temperature a little. If so turn up your lamp until your thermometer registers 103 or 104 . Be sure that you do not cover up the ventilators in the bottom of you incubator with the burlap, but place the openings in the burlap directly over the ventilators in your incubator so the air can come through the ventilators in the egg chamber and you will not smother your chicks.

\section{How to Pip the Egg}

$\mathrm{A}^{\mathrm{E}}$ FTER the chicks are all hatched that you think are going to hatch you can save a great many by pipping the shell yourself, by doing as I will tell you. I have saved as many as twenty in one hatch. First, break the egg at A. Strike it gently on the head of a nail or something very solid. Remove enough of the shell so you can see the : position of the chick in the shell. If the chick is alive you may find the membrane broken at $\mathrm{B}$ and the chick's bill protruding. If so place it in the incubator again till the blood has all been taken up by the chick and it begins to make exertions to get out, then remove the shell, providing it does not bleed. If you do not find the bill at $B$, then pip the shell at C. If the membrane or lining of the egg resembles greased paper open it with a pin to give the chick air till it is all finished up. You can remove a great deal of the shell 
if you will keep the membrane damp, and no harm will result. I have often removed nearly the entire shell before I could locate the bill. The chick must have air. Open the shell some where whether you find the bill or not. Sometimes the bill will strike the wing and cannot reach the shell, but the chick would be strong and healthy if you can only save it. Some one will tell you that a chick that cannot hatch without help is no

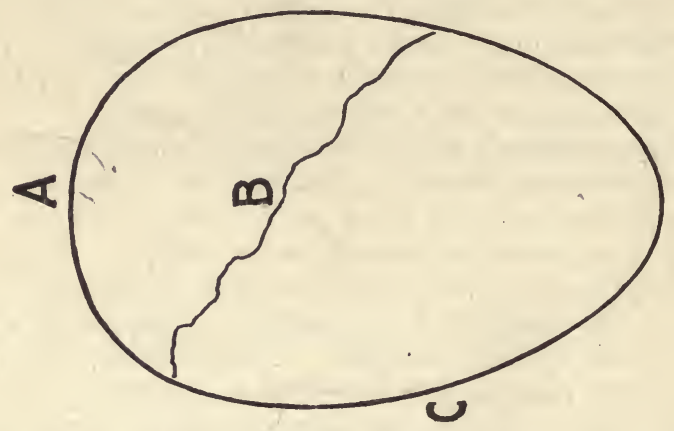

Diagram showing how to pip the egg

good. This is all a mistake. I advise you to save all you can, if you do have to pick them out of the shell, for you will lose enough after they are hatched if you happen to overfeed or overheat them. If you will remove the shell from those that die it will give you an idea of the exact position of the chick and make it easier for you to locate the bill. It will be a great help to you.

\section{How to Prepare the Brooder for the Chicks}

IRST, place paper in the bottom of the brooder, then cover the entire - brooder floor with dry sand, ( $d r y$ sand, mind you), to the depth of one-half inch, if the weather is quite cold. But if it be warm, onefourth inch will do. The feed room of brooder should have straw or timothy chaff scattered over the floor, so it will furnish the chicks exercise while waiting for their food. Place your lamp in your brooder about five or six hours before you want to put the chicks in it. Be sure the sand is warm and keep the temperature at about eighty degrees. If you have a good hatch the temperature will rise to about ninety degrees after the chicks are put in the brooder. This temperature, ninety degrees, should be kept for the first week or ten days, then gradually wean them away from the heat as their strength will permit. The operator can lower the 
heat gradually and still keep the flock comfortable. If the chicks crowd to the warmest part of the brooder and pile up, it is an indication of too low a temperature. If they move about with drooping wings and open mouths and sit outside of the hover, then the temperature is too high. There is no regularity known that will give as good satisfaction as the chicks themselves, as their actions will easily demonstrate whether they are too cold or too hot. The ventilators should be left part way open to admit fresh air, but no set rule could be given here just how wide they should be left open, as there are many different makes of brooders and much depends on the weather as well as the location of the brooder. The brooder should be kept absolutely clean, removing the sand and chaff every other day. Chicks in a good brooder, if furnished with pure, warm air at all times, and if the brooder be kept clean, will thrive and grow very rapidly, while on the other hand, if the brooder becomes filthy you may expect to lose nearly the entire hatch. The gas that rises from a filthy brooder is very poisonous to little chicks and causes dysentery. This becomes contagious and will go through your whole flock if you do not remove the afflicted chicks and clean and disinfect your brooders and brooder houses. This can be done with lime and sulphur. Whitewash your brooders and brooder houses with fresh lime. Air-slacked lime will not do; it is not strong enough. Then fumigate with sulphur. Remove your chicks to a place where they will be comfortable while this work is going on. The brooder must be dry before placing the chicks in it again. The whitewash will answer a double purpose; it will destroy mites and lice as well as cleanse your house and brooder. If you will always place a newspaper in the brooder before putting in the sand and chaff it will be a great deal easier cleaned. When your chicks are two weeks old you can use hay or straw instead of sand on your brooder floors. Change it twice a week until they are three weeks old, then once a week will do. Watch for mites; they can get in their deadly work in a very short time. They breed and accumulate very fast and will sap the lives of your little chicks before you hardly know it. Keep your lamp burners clean, also your wicks. Dirty wicks are often the cause of brooder lamps exploding. You can clean your lamp burners by boiling them in strong soap suds. Put your sand in pans and place in the oven and heat it. It will not take so long to heat the brooder if sand is thus warmed, before placing it in the brooder.

\section{When to Remove Chicks to the Brooder}

TF you have a good hatch, your incubator will become crowded before the hatch is done. Remove all the strong chicks that seem dissatisfied and crowd to the front of the incubator to the brooder that you have heated and prepared for them according to directions. Take from 
the machine only those that are lively and can toddle around. Now watch the temperature of your brooder. Do not let it get too warm, for just as soon as you put chicks in the brooder the temperature will begin to rise. Keep turning the lamp down and keep the temperature at about 90 degrees. I place my brooder in the kitchen or dining room for the first thirty-six hours, or until the hatch is all done and the time comes to feed them. It makes less work for the operator and you can watch the temperature of your brooder better. You may think it will not look well to put your chicks in the kitchen or dining room. Do not think any such thing. I would rather think it was an ornament even to the parlor, considering the prices of poultry and eggs for the last few years. If you can save your hatch by using the best room in your house for your brooder for a few days, do it, for it would be just like piling up silver dollars. If you have an early hatch, say in March or April, and you think it too cold to remove your brooder and chicks to the brooder house, first spread a newspaper in front of your brooder, and scatter a little sand and chaff over it. Nail some short boards together and make a little run. Then let your little chicks out for exercise and feed. If you have the room to spare keep this little run in front of your brooder for a few days and let the chicks run in and out at will. They will soon learn that the brooder is warm and will depend upon it warming them just the same as they would a hen. Remove the paper as often as it gets soiled, say twice a day. Scatter your feed, also a little timothy seed on this paper. This will give them exercise, for they will work and scratch and chatter and seem better contented than if they had nothing to do. After a few days, when the chicks have learned that the brooder is their home and mother, remove them to the brooder house. They will be stronger and can stand the cold better than they could if you had removed them there just after taking them out of the incubator. Sometimes in the spring, the temperature falls quite low in the night. You will have to watch this closely, as your chicks will pile up and smother. They will never pile up if they are warm enough. I always kill the cripples. They never amount to anything if they live, and all the time you put in on them is just wasted. Sometimes, on a rainy day, after the chicks are quite large, they will pile up in the brooder and smother or trample the weak ones to death. You can avoid this by making a fire in the brooder house. There are old second-hand stoves one can buy very reasonable that will answer the purpose. I have a stove in each one of my brooder houses and in the early spring I keep a fire all day so the chicks will not become chilled and take cold, They seem better contented, too. I cover the floor of the brooder house with dry dirt in the early spring; it keeps out the wind and makes it much warmer. I sprinkle ashes and a little lime over this floor and when the house is warm and the sun shines in on the floor the chicks will just make the dust fly. When this becomes 
filthy clean it out and put in some more. You will not have to clean it often. It is less work than scrubbing the floor.

\section{How and What to Feed Brooder Chicks}

IOR

$R$ years past every reader of the poultry and agricultural papers have read the statement, reiterated time and time again, that it is a comparatively easy matter to hatch chicks in incubators, but a difficult matter to raise them. So it has been, and so it is today. Feeding brooder chicks is the most important part of poultry culture. I have found this out by experience. I used to feed my chicks to death. I killed them trying to be good to them, consequently I have given the subject of feeding brooder chicks a great deal of careful study and have found at last how and what to feed them for best results. Do not feed the young chicks for from twenty-four to thirty-six hours after they are hatched, but allow them to pick at sand, charcoal, a little bran, and timothy seed, that has been placed in the brooder. At the end of twenty-four or thirty-six hours, to 200 chicks feed one-third cup of broken rice If you cannot obtain broken rice, just grind some whole rice in your coffee mill. Do not grind it very fine as a great deal will go to dust which will be a loss. Feed this raw and dry. Then in about three hours give them a drink of boiled, sweet, skimmed milk. Do not let them drink all they want of it for ten days, but just enough to moisten their food real good. In the evening give them one-half teacup of lettuce chopped real fine. This amount is for 200 chicks. Feed rice, lettuce and boiled milk but once the first day. The second day feed one-half teacup of rice three times, once in the morning, at noon and night, and one-half cup of lettuce at ten o'clock in the forenoon and one-half cup, chopped fine, at three in the afternoon. Give boiled sweet milk but twice a day for ten days, once in the forenoon and once in the afternoon. Do not put this drink in open dishes, or troughs, and do not try to water all at the same time, but make some fountains out of old tin fruit cans. Punch a hole about the size of a ten penny nail one-fourth inch down from the open end of the can. Put the milk or water in this. Place a saucer over the top and turn quickly and the milk or water will come out as fast as the chicks drink it. A quart can is the right size for a saucer and a pint can the size for a sauce dish. This prevents the chicks from getting wet. Water just a few chicks at a time so you will be sure they do not get too much, for they can founder on water or milk just as quickly as they can on feed, and it affects them just the same. Take a cracker box and put two of the can fountains in it, then put ten or fifteen chicks in it and watch them and see that they all get a drink, but not too much. After they have had enough, remove them to another box. Do 
not put them back in the brooder as you will not know which chicks you have watered. Now put ten or fifteen more in the box that contains the fountains and do just as you did before, and so on until they have all had a drink. Do this for several days until they all learn how to drink, then fix more cans, about six or eight to 200 chicks, so they can all drink at once, but do not let them have all they will drink. After ten days fill the cans with water and leave them sit till the chicks have had all they want, then you can keep water or milk by them all the time. Early in spring before you can have lettuce, cut clover or blue grass is a good substitute. They must have something green. Cabbage must not be fed to brooder chicks till they are four weeks old: it loosens their bowels too much. After the chicks are eight days old begin to feed a few bread crumbs and a little cracked wheat mixed with their rice. Feed this till they are three weeks old, then you can mix a little course ground meal with their feed. When they are four weeks old feed anything you please and as much as you please. You should feed ground bone or beef scraps three times a week after the first week, not too much at a time; it takes the place of bugs, worms, and grasshoppers which they would get if running with a hen. Every poultry raiser should have a bone cutter; it does not cost much and one can utilize every old bone and convert it into profit, which otherwise would be a waste. For best results in raising brooder chicks you must make the conditions as near like they were with a hen as possible. Scatter timothy seed and bran in the chaff in the brooder, also over the floor of the brooder house; it will keep the chicks busy and it would take a long time for them to eat enough to hurt them. The heavy breeds require a little more feed than the Leghorns or Minorcas, but do not feed too much. If you will heat the rice a little, the chicks do better and it will kill disease germs.

If you can keep your chicks healthy for two weeks, all danger is pas so far as feed is concerned, but watch your brooder and brooder house closely for mites; if they get a start in your brooder they will soon sap the life of your little chicks.

Do not feed any sour food or moulded bread to your chicks. Do not wet their food. Wet, sloppy food will cause dysentery, which is very fatal to brooder chicks because it is very contagious; it is liable to go through your whole flock if it once gets started. You should remove all chicks that are affected in this way and clean your brooder thoroughly, then close it up and burn sulphur in it. This will kill all disease germs.

After your chicks are twelve days old you can increase their feed. To 200 chicks give one-half cup of rice three times a day and one cup of lettuce twice a day. You can feed part rice and part wheat, 'or bread crumbs. Do not feed more than they will clean up; if they leave any, miss one feed. Count your chicks and measure your feed accordingly. I made 
arrangements with a Chicago firm from which to buy rice. I can buy it so that I can sell it for $\$ 3.00$ per hundred weight. This is cheaper than wheat for it does not require more than half as much rice as it does most any other kind of food. It is the best food for little chicks that can be procured; it is nutritious but nothing rich or greasy about it. There is not so much danger of bowel trouble when you feed rice. It is the best food I have ever tried and I have tried everything. Break up charcoal and scatter over the floor of your brooder house, or better still, pound it up real fine and mix it with chopped lettuce; it keeps their crops sweet and aids digestion. You must sow lots of lettuce; it will save so much feed.

\section{Early Hatched Chickens Are Best}

$\mathrm{B}$ EST results are obtained from early hatches-March, April and May. There are then not so many disease germs as appear later in the season, and you do not have lice and mites to contend with until June, July, August and September. You can hatch and raise chicks in June, July, and August, but you can raise a greater per cent with less trouble earlier in the season. I would advise every one to hatch their chicks as early as possible. The early chicks seem stronger and grow larger than those hatched later in the season. Another advantage in having early hatches, the pullets will commence laying early in the fall and if they have comfortable quarters and proper food, will continue to lay all winter.

I used to hatch chicks all summer, for I had but two incubators and could not hatch as many as I do now. After I hatched all I wanted for myself, I would hatch for my neighbors. In this way I could keep up expenses for eggs, oil, incubators, brooders, feed yard, etc. At one hatch this season I took 1,087 chicks from my incubators in one day. I advertised in the papers two weeks before my incubators were due to hatch that I would hatch 1,000 chicks on the 19 th day of July.

Many people have expressed the desire to come to my home when my incubators hatched, so they could see just what I did to obtain such good results. That is why I advertised that I would hatch 1,000 chicks on that day. I invited all to come, and about 100 responded. I exceeded my promise by eighty-seven and only lost twenty-three chicks in the shell. The weather was quite warm and my incubators, six of them, were all in one room. The animal heat in the egg kept up the desired temperature, so that I did not have any lamps under my incubators for four days before the hatch, and removed 975 chicks before I used any artificial heat at all. Then I collected the eggs that were pipped and those that were not and put them in one incubator, lighted a lamp and placed under it to finish 
the hatch. Those 1,087 chicks were hatched with the temperature at 103 degrees. Then the chicks seemed awfully warm. There is where I have made a mistake so many times, keeping too high a temperature at pipping time. I sold those chicks. They brought me about sixty dollars;.my eggs cost me twelve. Not so bad for three weeks work, was it.?

\section{How to Hatch Ducks by Incubation}

TT takes the same temperature and treatment for duck eggs as it does for 1 hen eggs, with the exception of moisture. Duck eggs require moisture while hen eggs do not. You do not introduce moisture into your machine, however, till the second week of incubation. Then, about every four days place a damp cloth (one thickness only) in the nursery or bottom of your incubator, leave it there until it is dry, then remove it until the time comes to replace it again. At pipping time shower the eggs and use the burlap just the same as you do when hatching chicks. Do not use the burlap for moisture during the hatch, as it is heavy and will hold more moisture than is required. I use an open flour sack. I wring it as dry as I can out of hot water. Watch your eggs at pipping time and turn all the pipped eggs with pipped side up so they will not smother. Do not place hen eggs and duck eggs in the same machine, as the treatment is different, also the time. It takes three weeks for hen eggs to hatch and four weeks for duck eggs, consequently the changes of the eggs take place at different times.

Brooding Ducks-Ducks do not need as much care as chicks; they can stand more cold and wet. However, I keep them warm for a few days, then let them run at will, but place them in a brooder at night, for rats, skunks and weasles are death on young ducks.

You can make a comfortable brooder for ducks out of a goods box. Just remove one board, so as to give the top a slant, replace the top, saw the sides even with the top, then take a piece of oil cloth or an old grain sack, or even a piece of muslin will do. Cover with common barn paint. If you put it on quite thick, one coat will do. I have made good coops for hens and chicks in this way.

The Pekin variety, above all others, seem to meet the market want best. They are the most popular, as well as the most profitable duck we have in this country. They are very large, creamy white, laying from 100 to 150 eggs each season. They are, as a rule, very easy to raise, mature quickly, and are the leading variety for market; do not require water except for drinking. Pekin ducks are, as a rule, very healthy, not being subject 


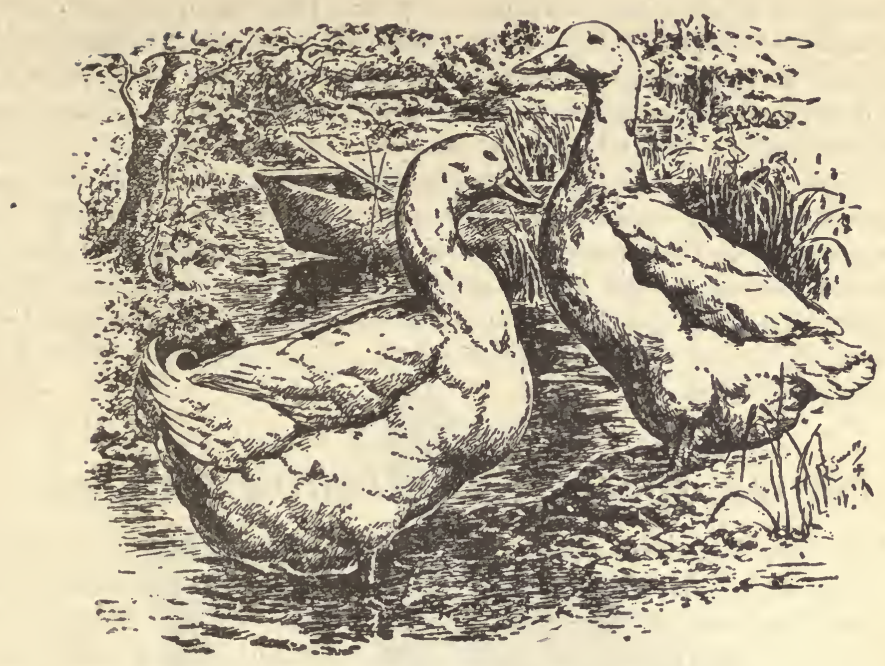

Mammoth Imperial Pekin Ducks

The Best Ducks Raised

to many of the diseases that poultry is heir to. The demand for Pekins was never as large as during the past year, thus proving their popularity, and that people realize there is money in duck culture.

\section{How and What to Feed Ducks}

TN the first place you should never keep ducks confined only for a day or two. Just as soon as they are strong enough to run after a hen turn them out.

You do not have to be as particular about feeding them as you do chicks and turkeys; they will eat almost anything. But for best results it is better to feed them cooked feed for the first week or two. Corn bread without any grease in it is good; also light bread soaked in boiled milk. After two weeks they will eat corn meal, boiled potatoes, beef scraps or most any thing you have a mind to feed them. They should have ground bone about three times a week and lettuce as many times a day as you have time to give it to them. Feed them lettuce from the start; they are very fond of it and will grow a great deal faster and do a great deal better than without it. If you have a hatch early in the spring before lettuce comes 
on, feed them alfalfa meal. Steam it or pour a little boiling water-over it to moisten and make it soft. It is a cheap feed for either chicks, ducks or geese, early in the spring, before there is any green stuff to feed them. Do not fail to plant lettuce every week and plenty of it. You can almost raise ducks on lettuce. It will lessen your expense for feed one-half. I have never raised enough yet to do me, but if I live I shall sow it every week this coming season. You can plant it in little nooks and corners of your gardens and fields that would otherwise lie idle. If you buy your seed by the pound you can get it a great deal cheaper. Ducks are more healthy when given plenty of lettuce. The Pekin is the most profitable breed you can raise; they grow fast and mature young. Keep plenty of fresh water by them at all times.

\section{Mating, Breeding and Rearing Turkeys}

\section{$\mathrm{T}^{\mathrm{H}}$}

HE Mammoth Bronze turkey is the acknowledged king of all turkeys. Plumage of the male on back and breast is a brilliant bronze hue, which glistens in the sunlight like burnished gold. Wing coverts are a beautiful rich bronze, the feathers terminating in a wide bronze band across the wings when folded, and separated from the primaries by a glossy, black, ribbon-like mark, formed by the ends of the coverts.

TAIL-Hach feather is irregularly penciled with narrow bands of light brown, and ending in a broad black band, with a wide edging of dull white or gray. In the female the entire plumage is similar to that of the male, but the colors are not so brilliant or clearly defined, and the edging of the feathers is generally a dull white or gray.

The Mammoth Bronze is the hardiest of all turkeys, and the most extensively raised of any breed. They are good layers, many claiming them to lay over 100 eggs in one season. However, there are exceptions in all things, but it is no unusual occurrence for a turkey hen to lay fifty eggs during hatching season, say from April 1st to July 1st. Most turkeys do not lay after the 1st of July.

To get the best results in mating and breeding turkeys the most important factor is the relations of the breeding stock, which should be strong, vigorous birds of both sexes, as we get enough weak turkeys without breeding for them. So if strong, healthy turkeys are to be expected, we must breed from the most selected stock that can be found. I am a lover of the bronze turkey. They are the largest breed of turkeys found and the most profitable, I think, of any turkey one can raise, although I have been raising the white turkey for several years, as my neighbors were raising the bronze birds, and I have had good success. Select the breed that suits you best, then you will be more apt to give them better care and 
advantages than you would a breed you do not like. Select females with good bone and long, deep bodies, with head and wattles as red as possible, as these qualities show good health. Avoid all extremes either in overgrown or small, weak birds. Those who use great extremes usually round up in the fall with very small flocks, while those who use better judgment in selecting their breeding stock almost invariably raise good flocks. Do not allow your breeders to become over-fat. Keep them in good condition and give them plenty of exercise. Turkeys should be allowed free range at all times, but keep them gentle and never frighten them. Teach them to nest near the house, if you can, by building appropriate nests for them.

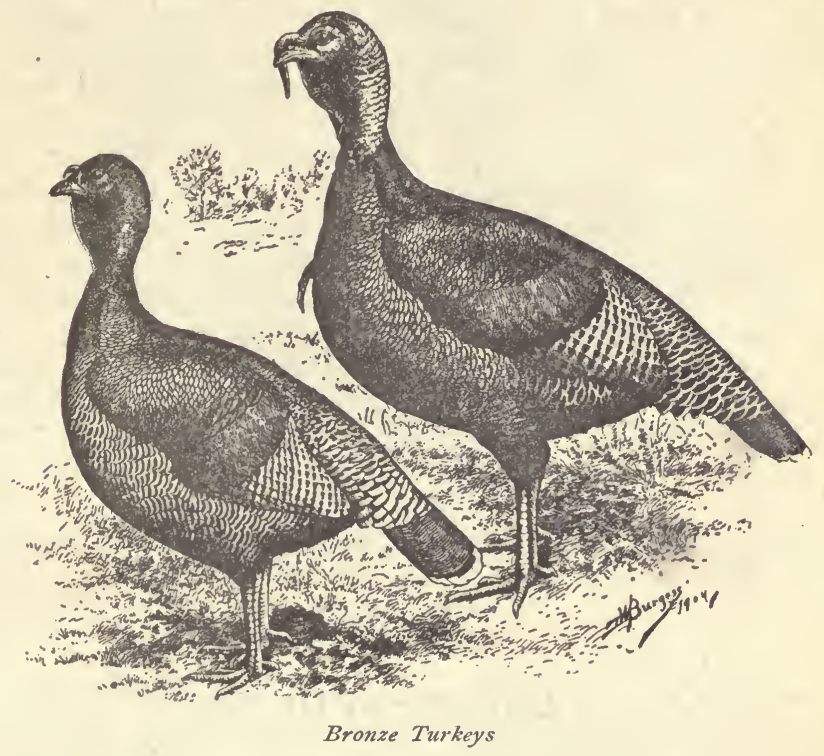

This can be done by laying empty barrels in fence corners or under hedges and placing brush and limbs over them. Put some straw in the barrel and leave room for some brush over the front of the barrel. They like such a nest and think they are hiding in a brush pile. If you let your turkeys go to the timber and make their nest, the crows are sure to rob their nests, or the eggs will chill, for we have some very cold nights after the turkeys begin to lay in the spring. If you can induce them to lay in the nests you have prepared for them, you can gather the eggs daily and place them where you can turn them each day until ready for incubation. Turkey hens 
make splendid incubators and rarely ever forsake the nest until their brood is out. I always give my hens from sixteen to twenty eggs each. This, however, will depend upon the size of the hen.

I always let my turkeys raise their own young as it is their nature to take them into the pastures and meadows where the insects, which furnish a great part of their food, are more plentiful. Turkeys raised around the poultry yard are more subject to disease than those that run at large. When I raise turkeys with hens I feed them boiled milk, and broken rice not cooked, lettuce chopped fine, a little bread soaked in boiled milk, charcoal and oyster shells, for the first week. Then I begin to feed a little ground bone; not much at first; it has a tendency to loosen the bowels. Feed them rice and light bread till they are three weeks old, then you can feed meal, or better still corn bread, but do not stop the rice and light bread entirely until they get used to the corn bread or meal. They should be fed three times a day.

Turkeys should not be cooped up or compelled to roost on the same spot each night, unless the coop be cleaned every morning and exposed to sun and wind so it will be perfectly dry by night. When large enough to fly up into trees, or on roosts, begin to feed them cracked corn, wheat and soaked oats. When the nights grow cold in the fall insects begin to die, consequently you will have to feed the turkeys more grain if you want nice plump fowls to put on the market at Thanksgiving. A great many times in the fall of the year you have small potatoes that are not marketable, also cabbage and beets, more than you can dispose of. They are excellent to feed to your turkeys. Boil the potatoes and beets, but the cabbage can be fed raw.

Sprinkle a little sulphur over your turkeys at night, if you have them in a coop. The lice will not bother so much if you do this.

\section{Culture of Geese}

Goose eggs do not hatch well in an incubator.

THE Toulouse geese are the most profitable to raise; they are an English breed. The bill and feet are a dark orange color. Both male and female are uniform in color; heads, neck and back a dark grey, breast light grey, beyond the leg to the tail they are pure white. They grow very large and live to a great old age. Goose raising is very profit able if one will manage it right, for they need no grain in summer, but they must have plenty of grass. If one would fence off an acre for geese you would be surprised how many you could raise on that one acre. I always set goose eggs under hens; they hatch better than with geese. I never pick my geese in the laying season, but I pick the ganders all the 
year round. I pick the geese in fall and early winter but not after February. In early spring when there is no grass I use alfalfa meal or cut clover to feed the goslings; they will not live without green stuff of some sort. Lettuce is fine for geese, but it takes lots of it. I used to plant a little lettuce in a box in the window in the early spring to feed to my early goslings; they liked it very much and did well on it. They will not bear

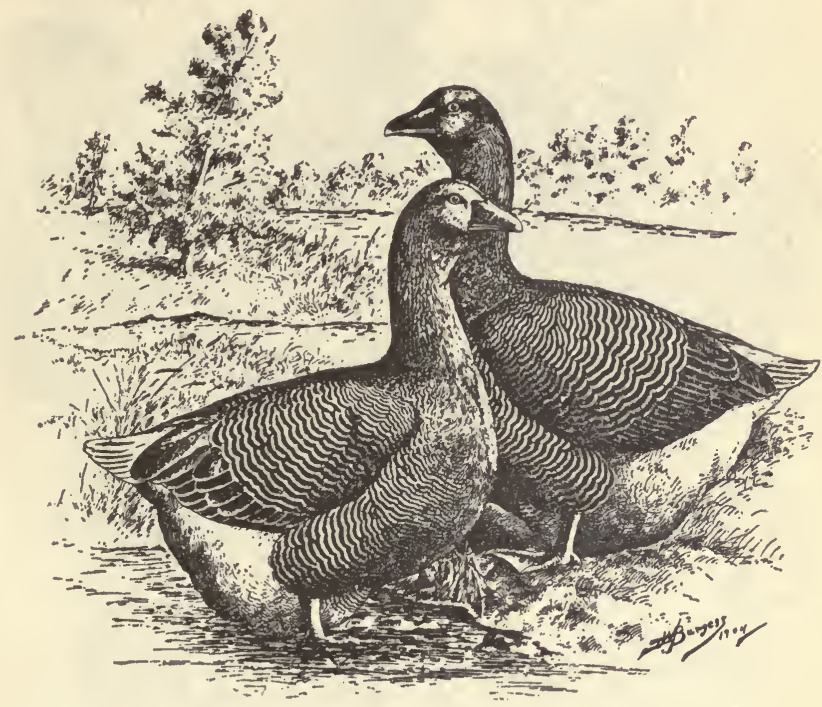

Toulouse Geese

confinement. An orchard is a nice place in which to raise geese. You should keep only what you want for breeding purposes through the winter for they eat a great deal of grain and are not profitable to keep for their feathers alone. They should be fed corn, oats, millet, wheat, speltz, or anything that will fatten them quickly in the fall, then put them on the market just as soon as you think the price will justify you to do so. As soon as grass is gone they are very expensive for they will eat all of the time if they can get food, so the sooner you dispose of your surplus the better. The Jews are very fond of goose meat and they use the oil for cooking the same as we do lard, consequently geese command a better price if they are quite fat. 


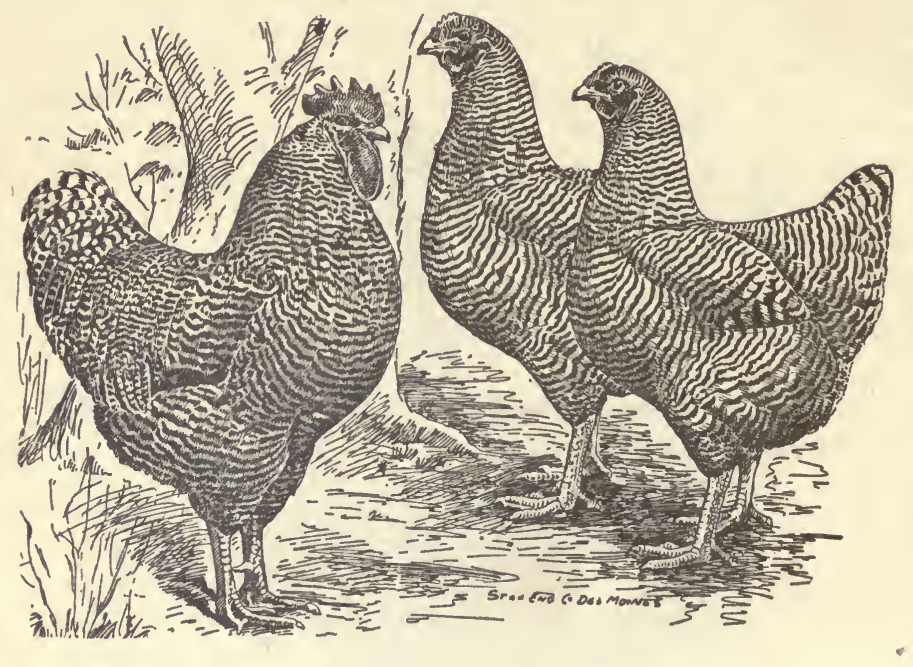

\section{Barred Plymouth Rocks}

This breed is as solid as its name; they stand acknowledged as the best general purpose fowl in the world today; they are quick to develop and make plump, juicy broilers at the age of eight and ten weeks. They are a great favorite.with market poultrymen who breed this variety more extensively than all other breeds combined. They are excellent all-the-yearround layers, and as a fancier's fowl have reached a popularity never before known. 


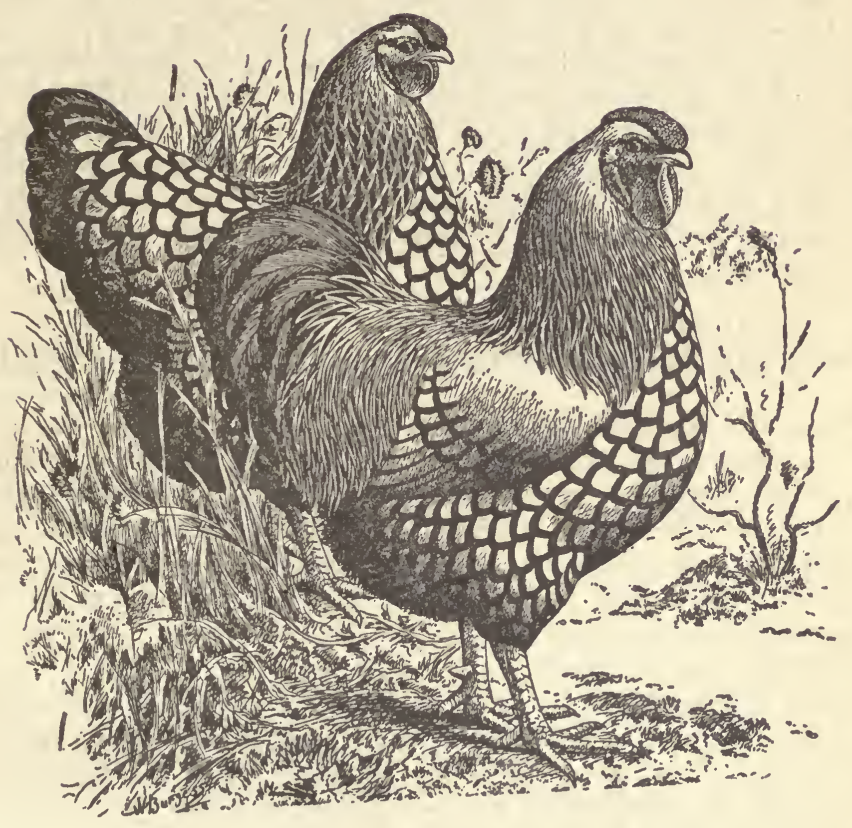

Silver Laced Wyandottes

This popular American breed is very beautiful as well as profitable, and for a table fowl are unexcelled. They are among the best layers, careful setters and their flesh is fine grained. They are hardy and mature early; have bright yellow legs and skin, and low rose combs; and combine all the good qualities of a general purpose fowl. 


\section{Which is the Best General Purpose Fowl?}

T FIND the Barred Plymouth Rocks or the Silver Laced Wyandottes are 1 the best for a general purpose chicken, where one wants to keep only a few. But if it is egg production you are after and do not care so much about the market quality of the stock, I would advise you to breed the Single Comb or the Rose Comb Brown Leghorn. There is no use to look any farther; they are good enough and the eggs are easily procured at reasonable figures, for so many people all over the country are raising them. They are hardy and do not require more than half the feed that the larger breeds do. I intend to lay in a supply of thoroughbred Plymouth Rocks and Leghorns this coming season and will try to supply my patrons with thoroughbred stock at more reasonable prices than they can procure them elsewhere.

\section{Feeding Hens for Egg Production in Winter}

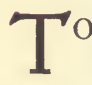

do this you must commence in the previous spring. Plant beets, carrots, onions, turnips, cabbage, potatoes, squashes, pumpkins, wheat, corn, oats, speltz and millet. You may think this is more of a variety than is necessary, but it is not. You must study what is required for egg production in summer, and make the conditions in winter as near like those of the warmer months as possible. You will have to have charcoal, alfalfa and clover meal to take the place of grass; crushed oyster shells and air-slacked lime to make egg shells; broken dishes or crockery to make a sharp grit to grind their food. If you can get good sharp grit or gravel it will do just as well, but we often forget to lay in a supply till after the ground is frozen, then we cannot get it. But the hen must get something of the sort, or they will have indigestion, and your chickens will droop and die. Broken dishes make a good substitute for grit. It should be broken up into pieces about the size or a little smaller than grains of corn.

This is how I feed my hens for egg production in winter, and have obtained good results: I feed corn in the morning, then about ten o'clock I feed them a mash consisting of boiled potatoes, chopped onions, alfalfa meal, charcoal, bran, shorts and oil meal. I give them this mash every morning. About twice or three times a week, I feed a little ground bone and blood meal in their mash. I give them baked squash, beets or pumpkin about three times a week. At about one o'clock each day I feed them oats that have been scalded; at about four o'clock I feed corn again. I give plenty of warm water, with a little sulphate of iron (copperas) in it; this keeps them healthy. Now you will think this a great deal of trouble, but if you will watch your hens after feeding them their mash and see how 
they relish it and how happy they seem, it will pay you for all your trouble. Besides, you will have the satisfaction of getting a nice lot of eggs at the time of year when prices are the highest. I am now selling eggs at twenty. five cents per dozen; that would be $\$ 7.50$ a case. Do you not think that price will justify you in giving your chickens a little more attention?

You must have warm houses for your chickens. I think every hen house should be lathed and plastered, which keeps out the wind and snow, and your hens will soon pay for the expense of plastering. I parch corn for them two or three times a week. It takes but a moment to put. it in the oven and it will be parched by the time you have your work done, so there is no time lost. I never feed frozen corn, but I take it into the house until the frost is out of it, or, still better, warm it. Always salt the mash a little. Chickens as well as animals require salt.

If your hens lay in winter you can set your incubator so much earlier in the spring. I have all my brooder houses plastered. One can rid their houses of lice and mites much easier when the houses are plastered than when they are only boarded up.

\section{Mrs. Johnson's Method of Forcing a Molt}

TO THE FANCIER: When a specialty is made of producing winter eggs, or preparing fowls for exhibitions, it is of much importance to have your fowls shed their feathers early so that the new plumage may be grown before the fairs, and poultry shows, and cold weather begins. In case molting is much delayed the production of the new coat of feathers in cold weather is such a drain on the vitality of the fowls that few if any eggs are produced until spring, while if the molt takes place early in the season your fowls begin winter in good condition, and with proper housing and feeding may be made to lay during the entire winter.

I have tried the Van Dresser method of promoting early molting, with results that were not very satisfactory. I was anxious to get the full benefit of a quick molt, so I fed my fowls very sparingly of oats, corn and speltz for about two weeks. I did not give them any green cut bone, or milk, which is the best egg producing food that can be fed to poultry. The consequence was, during the first week of the starving process, the hens stopped laying entirely, though they had been laying over 300 eggs a day. After two weeks, I put them on full feed again. I suppose I gave them too much on the start, for some becane crop-bound, some had bowel trouble, others indigestion, and the consequence was, I lost several of $\mathrm{my}$ nicest hens. They molted all right, but it was three months before they commenced to lay again. Some did not lay any until the next spring. 
Well, as the method of stuffing and starving was not satisfactory, I began to investigate. I read every article 1 could on how to force a quick molt, but all the papers and poultry journals advocated the starving and heavy feeding process. I finally thought of a method that I believed would work and resolved to try it at once. I took about fifteen hens and picked them. The result was charming. You fanciers will hail me with a cheer when you read this article. I plucked the body feathers first, then just as soon as the feathers began to come in, which was in about ten days, I plucked their wings and tail. By the time the wings'began to grow, the feathers on each side of the birds were large enough to support the wings. Within six weeks they had an entire new coat of feathers, and the most of them were laying eggs. Then I was provoked that I did not pluck the whole flock. This beats any method of forcing a molt that I ever heard of. It is more effectual, that is one thing certain. Your fowls have not been weakened by starving, but are in good shape to make a new coat of feathers at once. You must feed plenty of milk and green cut bone once a day for two weeks if you can possibly get it. If green bone cannot be obtained, meat scraps or cracklings will do, mixed with a mash consisting of bran shorts, alfalfa meal, charcoal, corn meal, oil meal, boiled potatoes, squash or anything that they will eat, but they should have a variety. Mix their mash with milk if you have it. After two weeks, feed this mash three times a week. Sometimes your hens will commence to lay before they are full feathered, under this treatment.

Fanciers that are preparing their birds for an exhibit should pluck them at least two months before they place them on exhibition. They will have an entire new coat of feathers and they will score much higher as they will be in good condition, the feathers will be more even and the markings or'colors will be more uniform by their all coming in at once than if allowed to drop out and come in one at a time. This sounds reasonable, does it not? It does not hurt your fowls to pluck them when the feathers are ripe and ready to come out at a touch, not a bit more than it does a duck or a goose. Then why not aid nature at this period?

After your fowls have gone through my method of forcing a molt, and begin to wear their new winter dress, their combs and wattles become red just like they do in the spring. They do not stand around all humped up for three months like they do if their feathers are left to come out of their own accord. They act like they were afraid of themselves for a few days, but soon come to the front for something to eat. If the feathers do not seem matured, and the skin bleeds, let those go till a little later in the season. July is the best time to pick your fowls, for the weather is warm and there will not be so much danger of them taking cold. Do not pick them on a rainy day. If fanciers would pluck their fowls just as soon as they are ready in July, then they will be in prime condition to 
place on exhibition in September. That is about the time that fairs and poultry shows commence. Put a little gasoline on a rag and rub over your fowls every morning while on exhibition; it will make their plumage shine so nice, and keep the lice from coming over on a visit from their next door neighbor.

I find another advantage in plucking my fowls in July. Eggs are cheaper then than most any time during the year. Then you will get eggs when prices rule the highest. This is the most pleasing and profitable part of it all, for those who keep poultry for egg production. This year I plucked all of my chickens. I am getting an abundance of eggs and selling them on the market for twenty-five cents per dozen. I did not get any eggs last year at this time except from the hens I had picked in July. Then I resolved to pick them all the next year, which I did with the above results.

Try this method of forcing a molt, dear reader, and you will find that your fowls will enter the winter in better condition than fowls that have been starved to produce an early molt. Do not fail to give them a tonic in their drinking water. Give good sharp grit. Here is where we of ten make a mistake. When the ground is snow-covered the fowls cannot get grit unless we have prepared it for them, and we often forget it until the ground is frozen and then we cannot procure it. Broken glass or chinaware makes a good substitute for grit.

I saved all the nice clean feathers that I picked from my chickens and made pillows to lie on the porch for the men to use while taking a rest at noon. It is a great deal nicer to use them in this way than to have them scattered all over the poultry yards.

\section{The White of the Egg Makes the Chick}

During incubation the chick derives its nourishment from the white of the egg and not the yolk. The yolk has nothing to do with the formation of the chick, but is the nutritious food which the newly hatched chick draws upon for sustenance during its early stages of existence. Consequently the chick requires no food until from twenty-four to thirty-six hours after being hatched. A chick can live without food for six days.

If Fertile EgGs Are Wanted-If fertile eggs are wanted you should have at least one cockerel to twelve hens of the heavy breeds, but one cockerel to fifteen hens of the light weights, such as the Leghorns and Minorcas, are sufficient; they are a smaller fowl, but they have more vitality than the larger breeds. 


\section{Find a Good Market and Meet Its Demands}

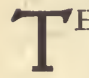

HERE is one thing that is of as great importance in the business of raising poultry as the feeding, breeding and management of the flock; it is the business of finding a good market and preparing the fowls for that market. It is true that anything that is well raised is half sold, but to say that anything is half sold is only half enough. We should be able to say that our stock is well fed, properly fitted and well sold. When we are able to reach this stage of the game then we are in a position to state what the possibilities of the business are. Remember that desirable goods always sell easiest. When market prices are ruling low, it is the best that obtains fair prices, while the culls are held over. The undesirable stuff should not be put upon the market; it will lower the standard of your better stuff. Keep the culls at home. feed them up and eat them, or sell on the home market, but do not ship them. This is not a matter of theory to be written on payer and to be read so as to enthuse people, but it should be put into practice, and those who put it into practice soonest will be the ones to make business a success. In every market there are those who follow out these lines and the poultry buyers know them, and their goods are always satisfactory and in demand. Markets, as well as how to raise poultry, should be studied. This is a matter that has more importance attached to it than it is given credit for. Study the markets and try to meet them.

\section{How to Prepare Young Cockerels for Market}

$\mathbf{T}$ is a waste of food to keep young cockerels after they weigh three or 1 four pounds each, as they are sold as "old roosters" after their combs grow. In the market, old roosters bring from three to five cents per pound, while young ones often sell from fifteen to twenty cents per pound. The best way to prepare young cockerels for the market is to separate them from the hens. Nearly every one has an old building of some kind they do not use in summer. That will do to put them in. Feed them soft feed, such as meal, potatoes and bran mixed in a mash, salt this a little and you will be surprised how much they will gain in two weeks. It will pay you to try it. Give them some green food, such as lettuce or cabbage. They must have plenty of grit and pure, fresh water, or sweet skimmed milk is better. They will grow as fast as capons and be ready for the market in two or three weeks, I think that caponizing is a cruel practice and is unnecessary. 


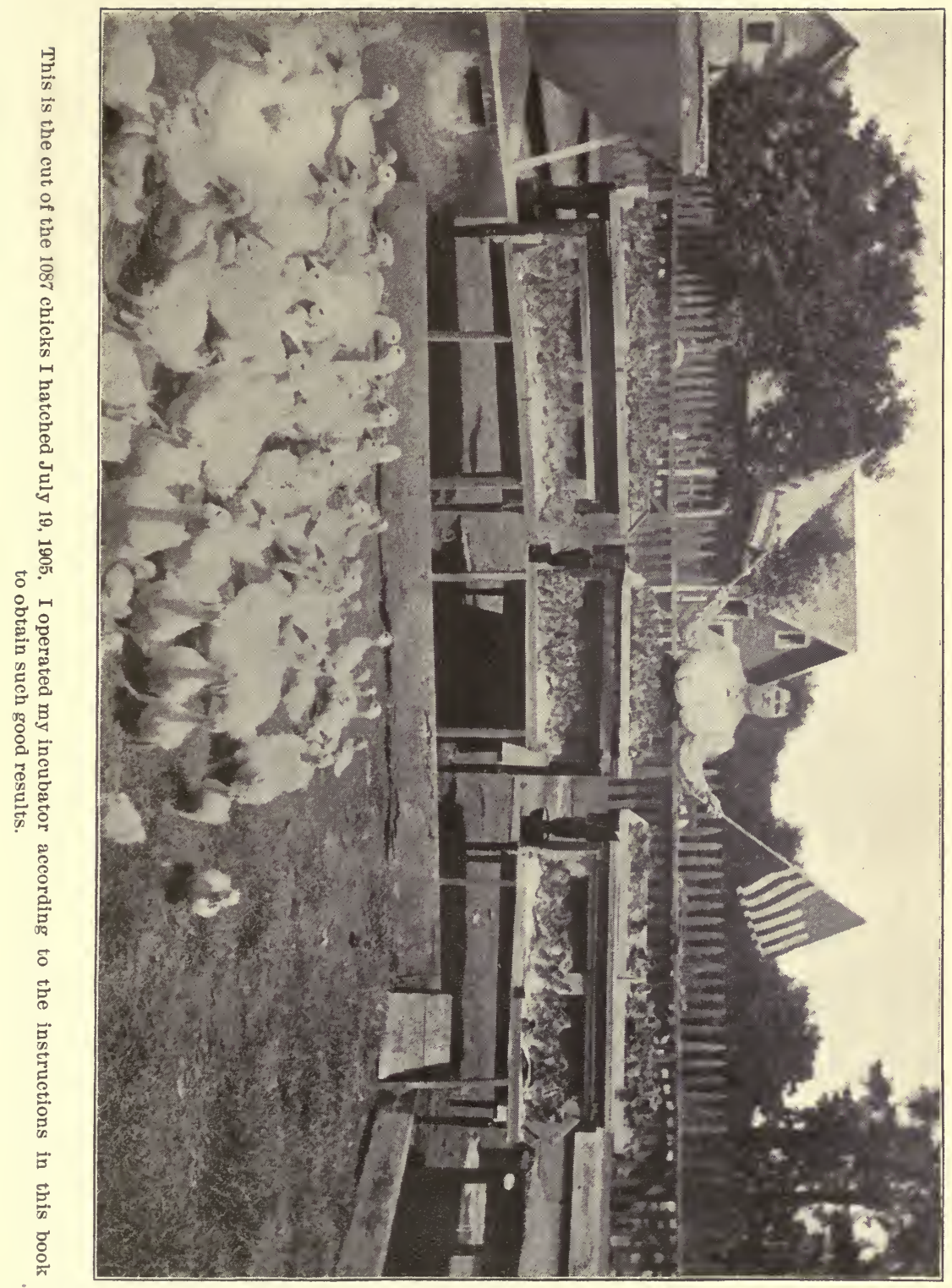





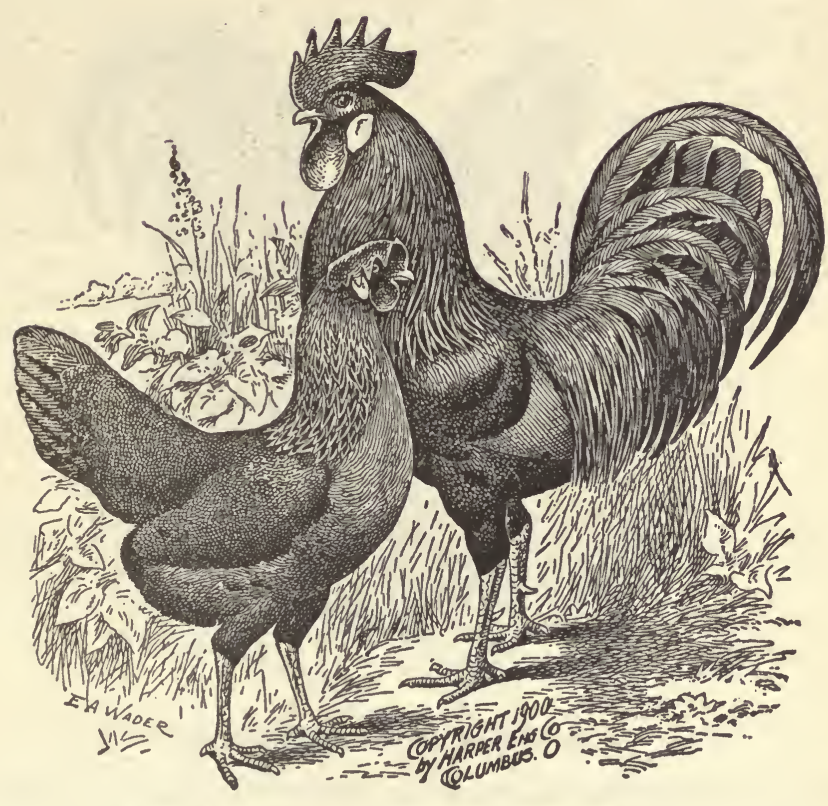

Single Comb Brown Leghorns

The acknowledged queen of the practical egg laying breeds is the Brown Leghorns when judged by the standard of the greatest number of marketable eggs produced at least cost. Not only are the hens persistent layers, but they are extremely active foragers and waste no time in setting. Like a good milch cow they put little fat upon their bones, but all surplus nourishment to egg production. The cost of growing them is comparatively light; no more, perhaps, than one-half that of Brahma or Cochin. 


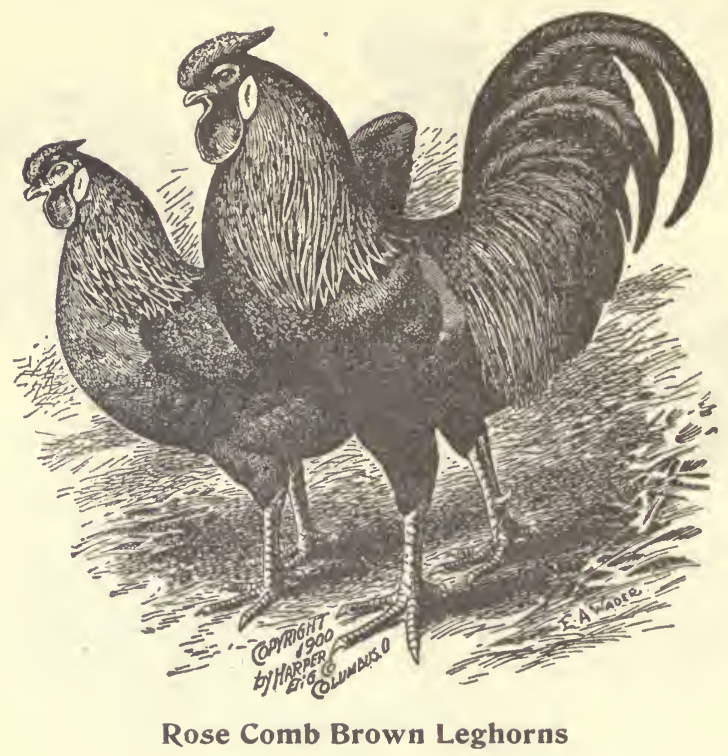

For a handsome bird and for egg producers the Leghorn stands at the head. There is no breed of fowls that lay so many eggs with little feed. Both the Rose and Single Comb Leghorn were originally imported from Leghorn, a seaport in Italy (hence their name.) The Rose and Single Comb varieties are exactly alike in every respect except the comb. The Rose Comb Leghorns are of medium size, have beautiful gay plumage, white ear-lobes and yellow legs, are symmetrical in form and very active and pleasing in appearance, are very hardy and chicks are easily raised on free range; they are good foragers and pullets lay at an early age. 


\section{Breeders and Success}

THE requirements of pure-bred poultry are constantly growing, more and more imperative owing to the demand by the people generally, the farmer as well as the fancier. The tendency of competition certainly demonstrates this to be an age of necessity. Rewards are not to be accorded to the amount of noise we make, but to the quality of the $\theta \mathrm{X}$ hibits; and certainly the more spirited the competition the better must be the systems adopted, the administrative ability of the poultry raiser being put to the test. Surely everyone will agree that the profits in any business are greater or smaller according to the management of that business, and we ought therefore to train ourselves to avoid all mistakes and calamities that have proved disadvantageous to success.

One can start now with pure-bred poultry so much cheaper than they could a few years ago, as so many have them all over the country and you can get them by paying a few cents more per dozen for the eggs.

\section{Leghorns Not Good Setters}

Leghorns do not make good incubators; they are too nervous. One should always keep some Plymouth Rock hens to hatch their chicks, provided they do not hatch by artificial incubation.

\section{Grow Speltz for Your Poultry}

CPELTZ is a new grain from Russia. It has been grown in the United $\checkmark$ States in a small way for several years, and each succeeding season not only emphasizes its value as a poultry food, but it is readily eaten by all kinds of stock. It is found to be adapted to a wide range of soil and climate; it resists drouth and will thrive on poor lands and is not readily damaged by harvest rains. It yields more per acre than wheat, oats, rye or barley. We raised last year sixty bushels per acre. This cereal is covered with a shuck enclosing two kernels that resemble wheat when the shuck has been removed, but the kernel is larger, The head is just about as long as wheat and resembles it very much only on speltz two kernels grow together instead of one. It is the very best food for egg production that I have ever tried, except wheat. It is just as good as wheat and is a great deal cheaper, as you can grow so many more bushels per acre. It is a very rich food and should not be fed exclusively. It should be ground for little chicks. 


\section{Recipe for Keeping Eggs}

$\mathrm{T}^{\circ}$ every three gallons of water add one pound of fresh slacked lime and one-half pint of salt. Have it well dissolved, drop in your eggs one at a time; mind, do not crack them. If you wish to keep them eight months or a year, you can do so, but you must use them or sell them as soon as taken out of the water, or they will spoil. When you have put in all you wish, take a thin piece of board and place on top of the eggs. Be sure they are all under the brine. Then cover the board with salt. Now place them in a cool cellar. Your eggs must be strictly fresh. It would be well to test them to make eure. This is a good way to keep eggs for winter's high prices.

\section{Talk on Incubators and Brooders}

$\mathrm{T}^{\mathrm{R}}$ RYING to save a few dollars on the first cost of an incubator often results in a very large additional cost through failure on the part of those so called "cheap" machines to hatch more than half of the eggs, and when the eggs are worth more than the machine, which is true in a great many cases, the spoiling of ten or twelve dollars' worth of eggs for the sake of saving two.or three dollars on the first cost of an incubator is, to say the least, very doubtful economy. Never buy a machine just because it is cheap. It may cause you lots of grief and many disappointments. If you have never had experience with incubators and do not know how an incubator should be constructed to do good work, go to or write to some one that has had practical experience and good success with incubatorsone in whom you have confidence and can trust. Ask their advice before purchasing a machine, then you will be sure to get a good one. Do not buy a sixty or hundred-egg incubator. You will have to spend as'much time with a small one as you would with a large one. A large incubator will cost you a little more in the start, but will save you money in the end, for it takes more oil to operate a real small incubator than it does a big one. The more eggs you have in the incubator the more animal heat there is, which helps keep up the temperature. Then you will have more to show for your three weeks' work if you operate a 150 or 240 incubator. If you do not want that many chicks at one time, sell them to your neighbors to help defray expenses.

One should have two brooders with each machine, because if you crowd your chicks they are more likely to become diseased than when they are kept in small numbers. You will have disentery to fight if you crowd your chicks. You should have a closed feed yard, like cut in this book, to attach to each brooder, provided you haven't got a brooder house. Fifty chicks will do better together than 100 . It is their nature to crowd just 
as close together as they can, and you are inviting disease when you put too many chicks in one brooder. Better put in just a few and raise them all, than to crowd them and lose the greater part of them.

\section{How to Build a Cheap Poultry House}

$\mathrm{T}^{\mathrm{N}}$ the first place you must keep your houses free from vermin, and when the nights begin to get cold and stormy, gather all of your chickens from the trees, sheds and out-buildings into the house you have prepared for their winter quarters. This house should be warm and roomy with windows to give light and sunshine. If you are a renter and haven't a warm house for your poultry, and the landlord does not feel disposed to build one for you, you can make a very comfortable house with a very little labor and no expense to speak of. If you offer to do the work the landlord will surely furnish the material. Pick out the location and measure off the ground the size you want to build your house. Then set two rows of posts three feet apart, nail on some poles or old boards, then pack with straw, tramp it down hard so that the wind can not come through; lay poles over the top and cover deep with straw or hay. Put enough on to shed the rain; put your window and door in the south side, and you will find you have a very comfortable house for your poultry. If the mites bother in summer, just throw out the straw packing and fill with new; burn the straw you take out so as to destroy the mites. Sprinkle Lice Killer all over the house and paint the roosts with it several times during the summer and you will have no trouble. Whitewash your nests with lime and sprinkle air-slacked lime over the floor of your hen house. It will keep your fowls healthy and help to rid your house of mites and lice. There is no one plan that could be given to build a good poultry house that would suit everyone. It will depend entirely on the location and the pocketbook. The papers are full of plans. Pick out one that suits your demands and means, but plaster the house by all means.

\section{Poultry Industry}

$\mathrm{T}^{\mathrm{T}}$ is possible that if an accurate census of poultry and eggs could be taken it would be found that the value thereof would exceed $\$ 300,000$,000. This throws the "fancy" part far into the shade. The great trainloads of poultry and eggs going to the large cities are what show the magnitude of the poultry interests. Then there is also the large number of eggs used in the arts. In the face of a great array of figures and facts, let the poultry business have its proper place, for it is the rival of any other. Cattle, horses, sheep, swine, and even wheat are falling to the rear of poultry. 


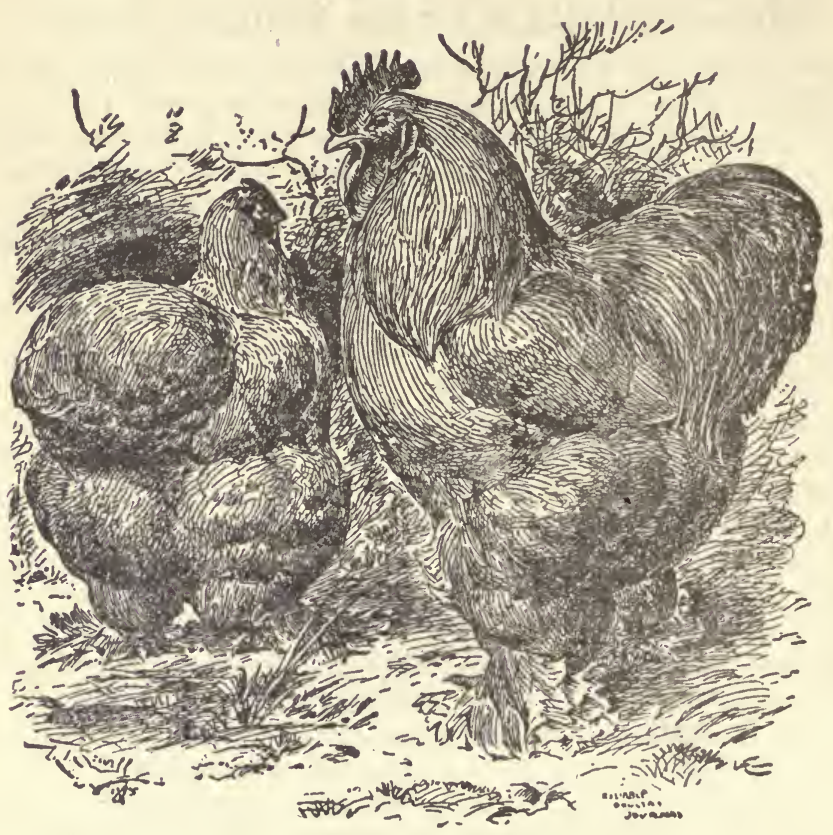

\section{Buff Cochins}

These are large massive fowls, profusely feathered, and have a very fine carriage. They are good layers, and will, under favorable circumstances, compare with the Leghorn class for winter laying, while for a market fowl they far exceed them. Like all Asiatics, they are rather later in maturing than those of the American class. They are heavily feathered and well adapted to cold climates. They breed true to color and are very docile fowls; can be easily yarded by a low fence and wire netting. 


\section{Bill for Closed Feed Yard}

One board $1 \times 10$ sixteen feet S. 1 S. for sides, cut in two.

Four boards ten-inch shiplap sixteen feet, for floors and sheeting.

One board ten-inch shiplap 12 feet, for ends.

One board $1 \times 14$ eight feet long S. 2 S., for door.

One board $1 \times 6$ eight feet, above the door to receive hinges.

Two pairs three-inch strap hinges, three for top door and one for little door.

Three window panes $7 \times 14$. Place these in the top door.

One piece of sheet iron eight feet long, for covering.

This size feed yard will accommodate as many chicks as you would dare put in one brooder. If you use a small brooder, say fifty or seventy-five chick capacity, you can make a smaller feed yard, say one-half as large.

On a great many farms one can find enough short pieces of boards to make a part of this feed yard, such as sheeting, ends and floor. The floor can be made of short pieces of common boards, put in crosswise instead of lengthwise, and stripped to keep out the cold. It does not need to be very high. Put a piece of oilcloth over the cráck of the door and under the sheet iron to shed the rain. Tack this oilcloth to door and under sheet iron. (See cut.) This brooder attachment, or closed feed yard, is the finest thing I have ever used. It is a creation of my own, and it does away with the expense of a brooder-house. Your chicks do better and are more comfortable than they would be in a large brooder-house, the expense is nothing compared to that of a building of that kind and it will accommodate as many chicks as you would dare put in one brooder. It is $3 \times 8$ feet, ten inches high and you can attach it to any brooder. It does not take so much capital to start in the poultry business when a closed feed yard is used instead of a brooder-house.

You should place the feed, water and chaff in the feed yard instead of the brooder, then your brooder will never get sour, which invites disease. The feed yard is very easily cleaned. You run the little chicks in the brooder, providing it is too cold to let outside, then clean the feed yard with a broom. In five minutes time you can clean it. Sprinkle a little air-slacked lime on the floor while it is damp, sweep it around a little. This will answer for a whitewashing and keeps the feed yard sweet and kills any disease germs that may be lurking there. I also clean my brooders in the same way. I burn sulphur in the brooders and feed yards twice a week.

The feed yard, likewise the brooders, should be covered with sheet iron, for your chicks must be kept dry. If they are covered with sheet iron or tin, it doesn't matter what kind of weather we have, they are perfectly safe for days. I have kept my chicks in the brooder and feed yard for two 
weeks in bad weather, and they were as comfortable as could be. They are safe from vermin, too, for nothing can get into this roosting place. One great advantage in having a feed yard is, the chicks have so much room, and the stronger ones do not trample the weak ones to death as they would if confined in the brooder any length of time. I never let my chicks out in the morning until the dew is all off the grass. I place the water and feed in the closed feed yard in the evening, after the chicks have gone to roost in the brooder. I sweep the feed yard first, if it needs it, place food, put more chaff and grit in, then close the door until morning. All I have to do in the morning is to open the little door between the feed yard and the brooder, and let my chicks out into the feed yard to their feed. I turn up the flame of the brooder lamp a little, so it will make it more comfortable in the feed yard, then I go about my work and do not pay any more attention to them until after the sun comes out warm and the dew is all gone, when I open the feed yard door and let them out. That is why I can raise so many chickens. This feed yard saves so much time; it is fine to put your chicks in after you wean them from the brooder. It is large and can accommodate almost a hundred grown fowls. In early spring I sometimes place a jug of hot water in the feed yard early in the morning, but this is not necessary only in cold weather. You should have two feed yards to each brooder, so you can use one for your three-weeks-old chicks that you have just taken from the brooder, to roost in so you can have the brooder for the next hatch. Be sure to close the little door between the feed yard and brooder at night so that the heat may be all retained in the brooder to keep the chicks comfortable. This feed yard and brooder can be moved to any part of the farm in just a few minutes. Sometimes it becomes necessary to move your chicks, so as to avoid disease. For the health of your flock, your brooder should be moved to a clean place often. Choose a nice grassy spot if possible. An orchard is a fine place and gives the necessary shade, which is very essential for the welfare of your little chicks in extreme warm weather. 


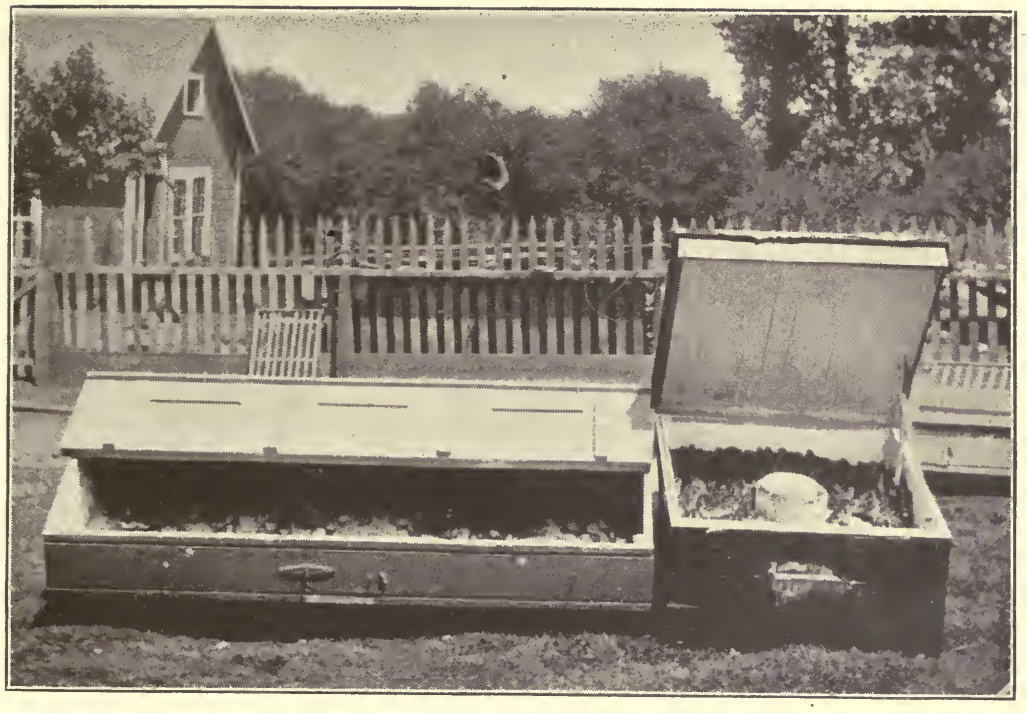

Feed Yard and Brooder-Open.

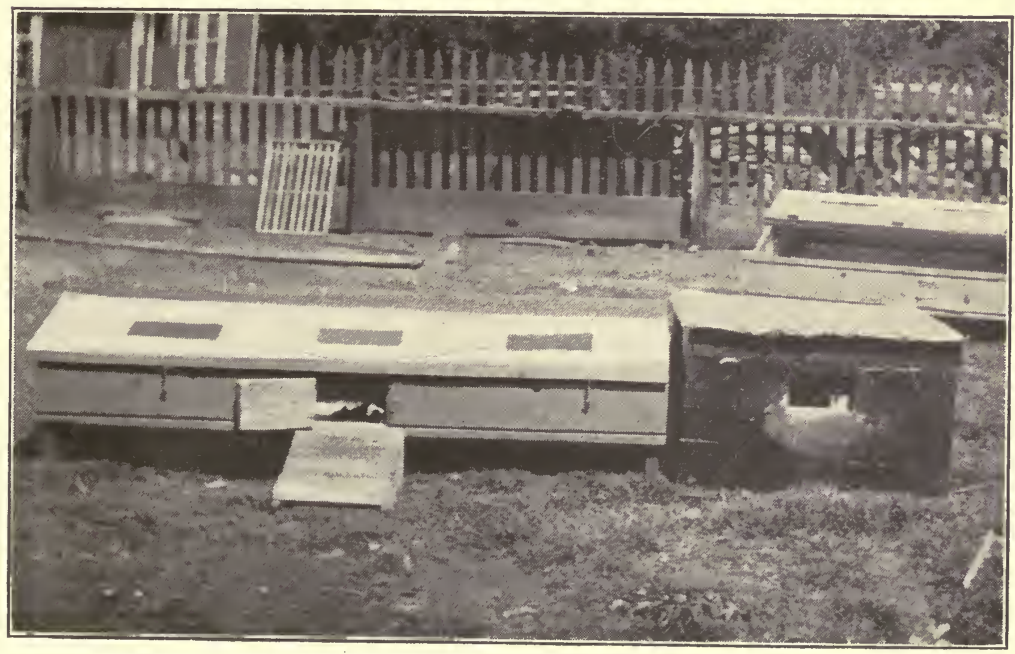





\section{Diseases and Their Remedies}

\section{Mrs. Johnson's Poultry Compound}

\section{Sure Cure for Bowel Trouble in Brooder Chicks}

T HAVE experimented for years to produce a remedy that would be a sure cure for bowel trouble in brooder chicks. Bowel trouble kills more chicks from ten days to four weeks old than die from any other cause. I have at last succeeded in producing a compound that is the best and cheapest of any remedy ever placed upon the market. It is not only a cure for bowel trouble, but it will cure roup, swelled heads and eyes, dysentery, crop-bound, leg weakness, cholera, and in fact every disease common among poultry; it will also keep your fowls in good condition, stimulate egg production, and for molting fowls it is indispensible. This is a critical time and fowls should have some kind of tonic to assist nature at this period. This compound is also good for wire cuts, sore shoulders and itch in horses and will cure foot rot in cattle; we use it for chapped hands, cold sores, cuts and bruises with good results.

I hatch and raise chickens by the thousands; have hatched as many as 1,087 chicks in one day. You can do the same, dear reader, by the help of this book, my Compound, good incubators, good brooders and good foed yards.

There are so many fakes in the world that I do not wonder if you doubt me capable of doing all I claim, but no one can give better references than these: State Bank of Maxwell, Maxwell, Iowa; editor of Maxwell Tribune, Maxwell, Iowa; First National Bank, Nevada, Iowa; editor Nevada Representative, Nevada, Iowa. These people have known me nearly all their lives. Write them.

If you bought this compound of companies that make a business of putting up compounds, the amount I will sell you for fifty cents would cost you just $\$ 4.00$, for they put it up in liquid form and sell it for fifty cents a pint.

\section{Directions for Preparing Compound}

To one 50 cent package of Mrs. Johnson's Poultry Compound add four quarts of water, after the compound is all dissolved then bottle it up and it is ready for use. 
Directions for Using-For a tonic to keep your poultry in good condition and stimulate egg production one teaspoonful to two quarts of water; for sick chicks one teaspoonful to one quart of water, if the chicks are very sick one teaspoonful to one pint of water; fowls with swelled heads and eyes, put one teaspoonful in one pint of water; wash their heads all over good and remove the matter from their eyes, put some of the liquid in their eyes after being reduced. Repeat this three times a day till they are well. Put some of the Compound in every thing you feed them, also in the drink you give them, whether milk or water; use a different cloth for washing each fowl, then burn it, this will prevent spreading disease. All affected fowls should be separated from the flock. Roup is treated in the same way, only you remove the cankers with a toothpick, then put some of the Compound quite strong, but not full strength, in their mouths with a feather, if you will commence in time and go according to directions you will save every fowl. To make a wash for sore shoulders, wire cuts and itch in horses put one teaspoonful of the compound (after being made into liquid according to above directions) into a half pint of water and wash the affected parts four or five times a day; to kill proud flesh ap. ply the liquid full strength, with a feather, there is nothing that will keep down blood poison better than this wash. For chapped hands, cold sores, cuts and bruises put one teaspoonful of the liquid in one-half pint of water, the only objection to using this wash, it stains the skin a little, but can be readily removed with citric acid or lemon juice.

If you bought this Compound of companies that make a business of putting up compounds, the amount I will sell you for fifty cents, would cost you just $\$ 4.00$, for they put it up in liquid form and sell it for fifty cents a pint. Now, friends, to prove to you that my Compound will do all I claim for it and more, on receipt of a stamped envelope and address, I will send a trial package of the Compound that will make one quart of liquid compound, then write me the results, please. At the price you cannot afford to do without this, it is a whole apothecary shop of itself, it is not only one ingredient, but many, that is why it will cure so many different diseases. Write me today. I can offer nothing more fair.

Mrs. Rebecca Johnson, Maxwell, Iowa.

\section{Cure for Dysentery in Chicks}

Cure for dysentery in chicks: One teaspoonful of acetate of iron, to each quart of water. Directions for using: One teaspoonful to one quart of water. Keep it before the fowls as long as they are affected.

Use the above until you can procure some of Mrs. Johnson's Compound, which is the best thing you can use for bowel trouble in brooder chicks. 


\section{A Good Tonic for Poultry}

Generally called Douglass Mixture.

A good and cheap tonic for chickens is composed of one pound of copperas, two gallons of soft water and one ounce of sulphuric acid, a teaspoonful being added to each quart of drinking water. This should be kept in a jug and properly labeled "poison."

\section{Grit for Poultry}

Grit is absolutely necessary for poultry. It should be kept with crushed oyster shell and charcoal in boxes constantly before them. They must have something during confinement in bad weather, especially, to enable them to assimilate their food. Broken crockery or china make good grit if gravel cannot be obtained. Oyster shell is indispensible.

\section{Dust Bath}

A dust bath should be provided in one corner of a room, well supplied with air. This bath should consist of slacked lime, ashes, road dust, a little sulphur and a little lice killer sprinkled over it.

Put one teaspoonful of Mrs. Johnson's Compound in each quart of water and give to chicks with dysentery. It is a good tonic at any time.

\section{Over=fat Fowls}

Do not keep your breeding stock too fat, as the eggs from fat fowls give poor hatches. Give fowls plenty of exercise. If birds have free range feed but once a day; if no range is available feed fresh, clean food three times a day and feed plenty of green stuff, lettuce, cabbage, celery, or anything that they will eat. Give plenty of fresh water three times a day. Cut straw, leaves or hay should be thrown upon the floor to the depth of three or four inches and in this the food thrown, to encourage exercise.

\section{Charred Bone}

Charred bone as well as charred corn is good for poultry, for the sake of the charcoal it contains, which is very beneficial to them in aiding digestion; but charred bone does not possess the full value of raw bone on ac- 
count of the animal matter contained in the latter, which is consumed in the charring process. Fresh bones when ground are the most valuable.

Boiled oats are good for chickens in winter, especially if you are feeding for egg production. It is a good feed at any time, much . better when boiled than fed dry.

\section{Diarrhoea and How to Treat It}

Diarrhœa in fowls is caused by worms, cholera, indigestion, lice, congestion or over-feeding.

Treatment-Seek the cause and remove it, if possible. A feed of corn meal and bran, made damp with a tea stewed from boiling white oak bark or blackberry roots will usually allay the trouble. Feed this for several days. Camphor is also good. I sometimes mix venetian red in their feed; it is a mineral and is good for indigestion. It should be fed to your hens twice or three times a week. Put Douglass mixture in the drinking water once a day at least. This is composed of one pound of copperas to two gallons of water. After this dissolves add one ounce of sulphuric acid. Keep in a jug; give a teaspoonful in a quart of water. (This receipt will be found on another page in this book.) Put remedy in a jug, for the action of the acid on tin would soon eat a hole through it. If this does not cure your fowls, write the author of this book for a trial package of her Poultry Compound. An addressed and stamped envelope is all it will cost you.

\section{Apoplexy}

This disease occurs among fowls that are very fat. The heavier breeds are most liable to suffer. The attack is sudden, no previous illness being shown. Fowls suffering from apoplexy often drop from the perch dead, or are found dead on the nest or expire from some slight exertion.

Treatment-Cut down the amount of food, especially fat-forming food, such as corn, and compel the birds to take exercise. Laxatives also are of advantage. A dram of sulphate of soda dissolved in a small amount of water and used to moisten the food for twenty to thirty chickens acts nicely as a laxative.

You will find remedies advertised in this book that are good for all diseases.

Globular salts in the water once a week will keep your chickens healthy. Look for lice and mites every day. They can soon get away with a brood of little chicks; they can soon sap the vitality of your hens and make them an expense to you instead of a profit. 


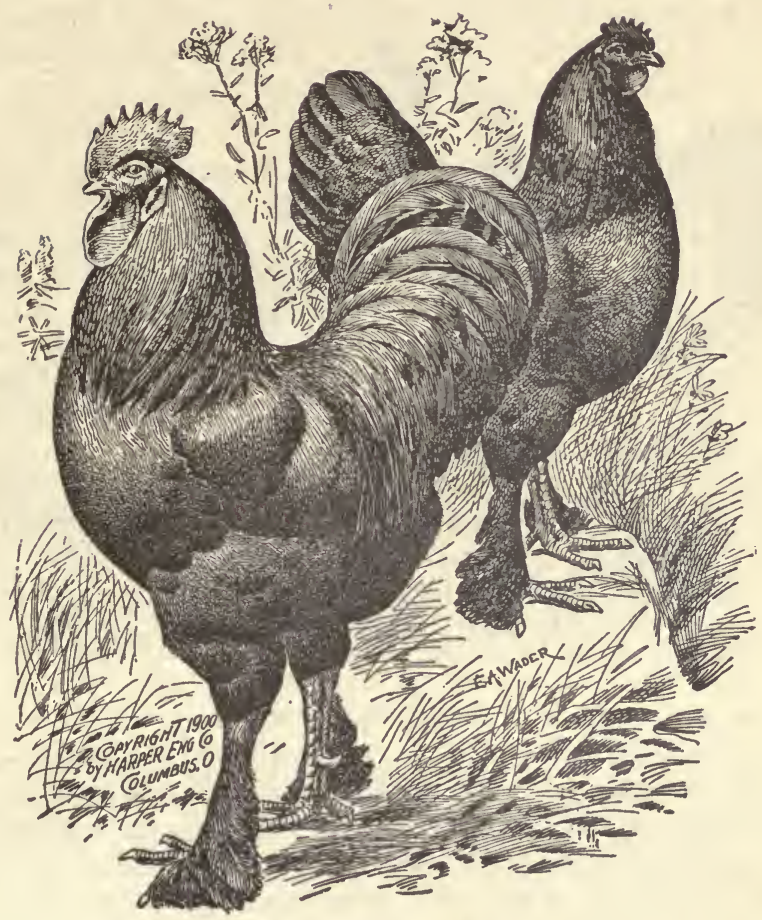

Black Langshans

Langshans were originally imported from China and are today one of the most popular fowls in the Orient. No variety of fowls ever gained popularity faster since their importation. The Langshans are large, stylish birds, with full, broad breasts, small wings and erect, small combs; their bright red wattles, ear lobes and combs, glowing against their glossy black feathers, form a striking contrast. 


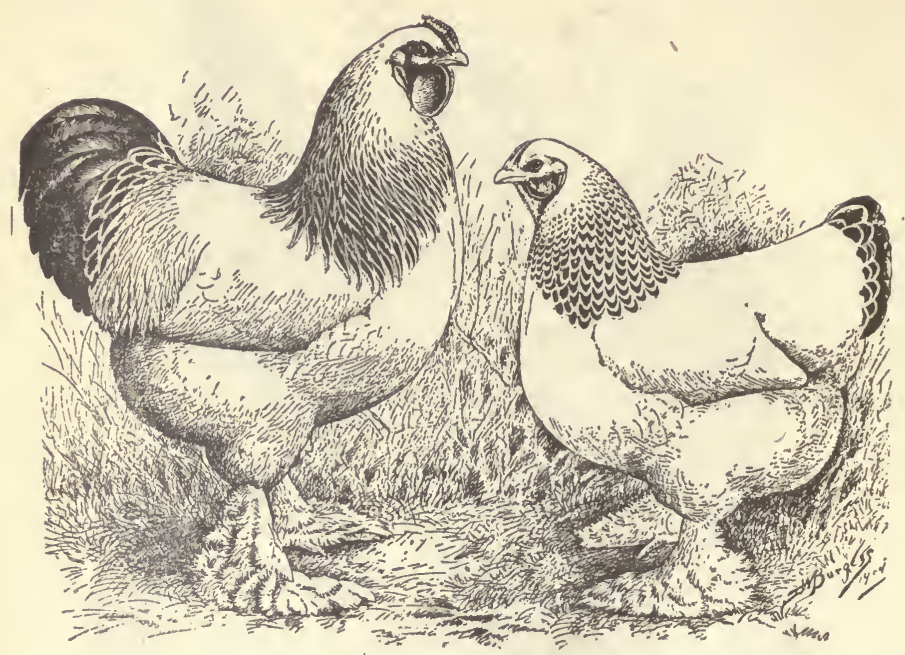

\section{Light Brahmas}

The Light Brahma, by unchallenged right, stands at the head of all thoroughbred poultry. During the past thirty years, while other breeds have had their "ups and downs," the Light Brahmas have stood their own ground, and today they are as much praised and as highly recommended to the general breeder as they were thirty years ago. Any breed that can stand the test of rivalry so long and still continue to satisfy and please the thousands breeding them, must have qualities of a high order. They are the largest of all our poultry, and furnish more pounds of flesh and eggs in twelve months than any other breed of fowls on earth. When full grown the cocks weigh twelve pounds and the hens ten. They are well adapted for all purposes, and are so gentle, handsome and practical, one cannot help but like them. 


\section{Cholera}

Sxмpтомs-The first indication of disease may be shown by the bird appearing slow and indifferent, remaining alone, half asleep, with drooping wings. The head is pale or bluish white. The excretions, which in health are white, are tinged with yellow.

CAuses-This disease generally arises from filth, lice, poor ventilation, over-crowding, improper food, filthy water, etc.

Prevention and Cure-Heat destroys the cholera germ. If the food or drink be boiled and fed from vessels cleansed with boiling water it will remove this source of infection. All healthy birds should be removed from the infected pen. Remove all the droppings or other filth. Whitewash the house and roosts, cover the floor with lime and ashes; then burn sulphur every few days until the disease disappears. Keep the sick fowls away from the pen or house.

Treatment-Give a teaspoonful of castor oil to each fowl and feed just the same as for diarrhoea; give Douglass mixture to drink; give oil once in two days.

\section{Cure for Scaly Legs}

If your chickens have rough, scaly legs, put some kerosene in a can and hold their feet and legs in it for about five minutes. If the first application does not cure them repeat it once or twice more if necessary. This disease is caused by a parasite and is readily cured with kerosene. You can cure the bumble foot in the same manner. The bumble foot causes the feet to swell and the fowl will get very lame and will finally droop and die if not cured. It is contagious and should be treated at once.

\section{Crop Bound}

This disease arises from taking too much or too course food into the crop; it is frequently the result of an abnormal appetite from deranged digestion or lack of variety of food.

Treatment-A little oil and tepid water should be poured down the throat and the mass in the crop kneaded gently to aid in breaking it up. A small quantity of soda dissolved in water will prevent fermentation of the food in the crop. If the mass does not leave the crop within three hours, it may be necessary to cut through and remove the contents. Cut as high as. possible so that the food taken afterwards, which should be limited for a few days, will not escape. Sew the crop and skin separate. The 
fowl will be all right in a few days. I have often treated fowls. this way, with good success. Feed plenty of crushed oyster shell and sharp grit at ail times. This will prevent fowls' crops from becoming bound. Give copperas or Mrs. Johnson's Compound in their water every few days.

\section{Cure for Roup}

The roup is a very dangerous disease, and a hen with roup may spread the contagion by drinking water from the same receptacle as the others, for the exudation spreads out on the water. Hens sleep with their heads under their wing and the pus that comes from their eyes and nose stick to the small feathers. These come out and other hens that pick at the feathers will get the roup. The only way to prevent this is to separate the sick from the well fowls and clean up the coop thoroughly. Close up all the cracks as they are a fruitful source of roup. In cold weather close your coop so that no cracks are open, and when the weather is warm keep the door of the coop wide open. The sick fowls must be kept in a warm place until they recover. Bathe their heads with warm water, then grease their heads and throat with kerosene and lard, equal parts; give. each sick fowl a teaspoonful of castor oil; feed them a warm mash of bran, cut grass or clover, meal, a little onion and meat scraps If they are very sick cut their heads off and burn them; do not throw their carcass where other hens can pick at them.

If the above does not help your fowls, send a stamped and addressed envelope for a trial package of Mrs. Johnson's Poultry Compound, or send fifty cents and I will send you enough compound to make one gallon of medicine. This compound I guarantee to cure roup, cholera and diarrhoea in old and young fowls, if given in time. 


\section{Poultry Hints}

Feed alfalfa meal in winter.

Air castles like eggs are easily crushed.

All classes of poultry are fond of fresh ground bone.

Close application to every detail makes success sure.

Grit, fresh water and bone meal for health and eggs.

Hot, strong whitewash on a wall is light, sweet and cheap.

Allowing the fowls to drink impure water is inviting disease.

Have all brood coops well made, as they should last for years.

In the poultry business, common sense is the thing most needed.

The chick whose life blood is being sucked by vermin cannot thrive.

A saturated solution of boracic acid is good for swelled heads and eyes. winter.

Clean, dry quarters are needed for health in summer as well as in

Raw corn meal mixed up with water is not a proper food for young chicks.

Scatter fresh slacked lime liberally over the hen house; it will aid in preventing disease.

Keep your poultry house clean. Then you will always have healthy chickens.

Flat perches are best, because they are more comfortable for the feet of the fowls.

Dark-shelled eggs have proved harder to test for fertility than lightshelled ones.

Slacked lime placed in the drinking vessels will of ten cure the hens of laying eggs shell-less.

Insect depredations are like weeds; they can be kept in check by preventing their getting a start.

Ducks are cholera proof, roup proof, gape proof and hawk proof, but will sometimes die of spinal meningitis and paralysis. 
Always arrange the nests so that the hens can step in rather than jump down; they are apt to break their eggs in jumping down.

For the good of the flock remove any fowl that shows any signs of being sick, even if the ailment is slight; it may save you a lot of grief.

There is not very much danger of overfeeding chicks after they are four weeks old, but they should be fed in some place to which laying hens do not have access.

Remember to keep the poultry house clean and free from filth of all kinds. Filth is the source of most diseases. Lice will account for what filth is not responsible for.

There is a mistake made in buying extremely heavy weights for breeding Select birds about the standard weight for the chosen breed and get them thick-fleshed and solid.

Shut up the hen house as tight as possible, occasionally, and burn sulphur in it; the fumes will reach every crack and crevice and be death to disease and vermin hidden there.

There is no food as corrective in the way of a digestive that equals charcoal. It is easily obtained because various forms of the article may be made by the poultry raiser himself.

Poultry in the orchards, in addition to thriving themselves, are of great benefit to the orchard in that they destroy insects, bugs and worms, and keep the trees in good condition.

The swill barrel and often the slop pail have proved a watery grave for many a fine chick. Covers over them will prevent this. Moreover, covered barrels and pails attract less flies than uncovered ones.

Incubators that have been used all season should receive a good, careful cleaning and be well aired and sunned before storing away. If your incubator is a hot water machine, be sure the pipes are all perfectly dry.

Do not put a floor in the poultry house if it is possible to have a perfectly dry one without it. If dampness is likely to get in, make a cement floor and keep it covered with litter of some kind-straw, leaves or hay.

The road to success in poultry keeping which reaches the goal of profit is not all smooth and level. When the road is most difficult the owners must drive; for personal observation is necessary to avoid rocks that wreck.

The every day welfare of the hen is a matter of method. Every streak of ill luck that has assailed your ambitions can be traced to something neglected, and that streak of ill luck can be traced to ourselves, but we do not like to admit it. 
Salt is an essential part of the poultry ration. One of the best ways to give it is to mix it with soft food. In this way it will make the food more palatable as well as assist in digestion and keep the hens in good condition. A small quantity daily is much better in every way than a large quantity occasionally.

Always keep the hens supplied with green food as late in the season as it can possibly be done by turning them out to secure any such that may be within their reach. When the supply is failing put cabbage in the poultry yard. After snow covers the ground, feed alfalfa meal, fine chaff or sweepings of the hay loft.

A bone cutter was once thought a luxury, but is now considered an absolute necessity. You can not make a commercial success of poultry without one. If you feed green cut bone to your fowls, the increase in the egg product will pay for a bone cutter in a very short time, besides it will keep up the vitality of your breeding stock and make more fertile eggs.

Worms in the windpipe are the cause of gaps. One can ofttimes remove them with a horse hair. Double the horse hair and make a loop, insert it into the windpipe, then draw it out, repeat this several times. If the worms are not too far down the windpipe, you can get them every one. You cannot give your fowls medicine strong enough to remove the worms without injury to the bird.

There is one valuable advantage of keeping poultry on the farm that is generally overlooked and that is the vast number of insects destroyed by them. If you will plant plum trees around your poultry house you will alway have plums. The hens destroy the larvae of insects that infest plum trees. The trees furnish shade that is very necessary for chickens in hot weather. You should utilize every foot of ground in a poultry yard for fruit trees.

Dear reader, are you desirous of bettering your condition financially and thus enjoy a little more of this world's happiness, seeing your family prosperous and contented and adding each day a little more to this world's store? Would you like a business in which you can become your own master, direct your own affairs and in short be independent? If so, I would advise you to go into the poultry business. There is more profit in it considering the money invested and the labor required, than in any other enterprise you can engage in. It takes a young fortune to equip yourself for farming, and another fortune to pay rent. And what have you left at the end of the year after your expenses are all paid? A meager living, lost hopes, a discouraged soul, and a yearning for something better. 


\section{Give Your Boys and Girls a Chance}

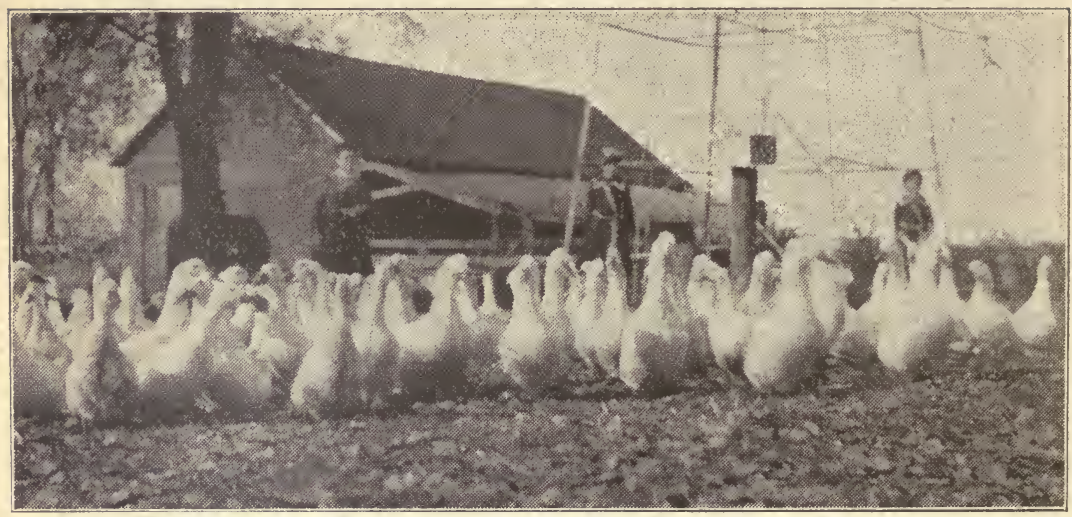

Mrs. Rebecca Fohnson and Her Little Daughters, Veta and Bessie and their Ducks.

THIS is the picture of myself and two little girls, Veta and Bessie, and 1 their ducks. Last spring my little girls asked me if they could raise some ducks and have the money they received for them when sold, for their very own. They had some money which they had earned building fires at the school house, and doing odd jobs at home for which they would receive a nickle or a dime. This was all put together in a pocketbook which they called their bank. In February they sent an order to Des Moines, for a trio of Pekin ducks for which they paid $\$ 7.00$, including the freight. This they thought was pretty high, but they wanted to start right and wanted the best they could get. They received fine birds. Then we bought an incubator and every morning they would gather the eggs early so they would not chill. They placed them in baskets and turned them once each day. They did this without being told. I set the incubator and lifted the trays; they filled the lamps and watched the thermometer, and kept the egg chamber at the proper temperature for incubation. They did this just as well as I could have done it. When the ducks began to hatch how delighted the girls were. They would stand in front of the incubator and look at them through the glass and talk all sorts of baby talk, telling them what they would do for them as soon as they would be able to leave the machine. They never took one-half the 
pleasure with all their dolls as they did with those ducks. They hatched some of the ducks with hens. The girls fed, brooded and took all the care of them. I paid no attention whatever to them and the result was they sold fifty-six dollars' worth and kept thirteen ducks for breeding purposes. $\mathrm{O}$, the air castles they are building for another year!

Mothers, try your little girls and boys in this work; it will surprise you what an interest they will take and how many steps they will save you during the summer, besides the practical knowledge they will gain that will help them in after life. We have their music lessons and musical instruments to pay for anyway. Why not give them a chance to earn the money to pay for a part of these at least. They will practice more economy in spending the money they earn themselves than if it eame direct from us. They will also take more interest in their music and try harder to learn when they pay for the lessons with their own money. This is not all. It will be an advantage to them to learn things along this line while we are here to teach them. Labor rarely becomes irksome to children when they are personally interested in it, knowing they will receive, the profits derived therefrom. 


\title{
Testimonial Letters to Mrs. Johnson
}

\begin{abstract}
THE following letters received by Mrs Rebecca Johnson are an indication of the appreciation people have of her knowledge on the subject of manipulating incubators and raising chickens:
\end{abstract}

Nevada, Feb. 3, 1905:-Dear Mrs. Johnson: I feel as if I must write and thank you for the letter you wrote me how to run an incubator. I used to read all the books and papers about poultry and incubators that I could get, but your one instructive letter had more valuable information in it than all papers and poultry books I ever read. It told me every thing in plain words, just what I needed to know. I think that the failure in incubators are due to improper instructions sent out with the machines. The first time I started my incubator I ran it according to the directions I received with my incubator, and failed. I only got forty-four chicks from 230 eggs; I became very much discouraged for I wanted early chicks, but when I read in the papers about your success I thought I would write and ask you how you managed your incubator, and received your letter just in time to save my second hatch; this time I got 146 healthy chicks and the third time I got 164. I hatched quite a few under hens for I wanted the hens to raise the incubator chicks. In all I raised about 500 chicks. It was late in the season when I got your letter; next spring I will start my incubator early and try to raise twice as many. I have a brooder, but I do not know how to use it; I wish you would be so kind as to give me instructions how to operate it also; it would be so much easier than to bother with hens. I have a nice flock of Langshans. I like them the best of any kind we ever had. Please answer soon.

From your friend,

MrS. L. C. RIERSON.

Colo, Iowa, May 23, 1904.-My Dear Mrs. Johnson: I received your kind letter and will say I was glad to hear from you for your letter did me so much good. I have been waiting to see what kind of a hatch I would have. Well, I was happily surprised. I hatched 380 chicks from 400 eggs. This is the best I have ever done. From the hatch just before this I got only 132 chicks from 400 eggs. This was before I received your letter. I operated the ventilator just as you told me. If everyone knew just how to operate their incubator and have as good success as I did, they would be spared lots of grief and many disappointments. I wish you would 
write me again and tell-me anything you think I ought to know. I am always ready and willing to learn. When I read of your success, I wondered how you managed your incubator for such good results, but when I read your instructions, how easy it was for me to operate my incubator. I wish I could sell my incubator; it is almost too large for me since I can hatch so many chicks at once. It is a good machine and if a person will follow your instructions they can hatch more chicks than they can take care of. As I know how to operate an incubator now, a smaller one will do me just as well or better, than a large one. My family is small, only my husband and myself, but I want to raise at least 500 hens for next year. I think it is the duty of every woman to do all she can to help make a livelihood, don't you? And they can help more by raising poultry than any other way. It is a work I dearly love. I would like to meet you and have a talk with you. Thanking you again for your kindness, I remain

Yours very respectfullp, Mrs. Ed. DaY.

Colo, Iowa, Oct. 10, 1905.-My Dear Mrs. Johnson: Please send me another fifty cents worth of your Poultry Compound. We have hatched at least one-fourth more chicks since you showed us how to put those extra ventilators in our incubator. I do, indeed, feel grateful to you. Your book is certainly a wonderful help to chicken raisers, no more so than your Compound. I am glad there is some one coming to the front to help us women in poultry raising, for men have so much help in their stock raising and one is just as essential as the other, don't you think so? We have had good success with our poultry this summer. Please send the Compound by return mail and oblige,

Yours respectfully,

Mrs. John Connoly.

Kalona, Iowa, Sept. 22, 1905.-Mrs. D. C. Johnson, Maxwell, Iowa: Kind Friend-Well, I will at last write and let you know that I received the money all right. I simply put off writing from one day to the next, and so time went. I had a letter from my daughter, telling me that she saw you at the fair. She also sent me your card and the price of your poultry tonic. You please send me a package for the stamps enclosed. We have sold enough young chickens to pay all our expenses and have about 200 young chickens left for clear profit. My success is all due to you and your valuable instruction book, I am well pleased with the incubators I bought of you. Of course, we have not the numbers you are used to raising, but I am proud of my success as a beginner with an incubator. Have you the pure bred Plymouth Rock cockerels, and if so what are jour prices? I did 
not expect the dollar back on the incubator; only the freight. I thank you very much for the same and for all favors you have done for me.

Yours respectfully,

Mrs. Barbara KemhF.

Nevada, Iowa, Sept. 20, 1905.-Dear Mrs. Johnson: You gave me a trial package of your poultry compound at the fair. I know it helped my chickens, so I will enclose enough to pay for your poultry book and fifty cents worth of your Compound. Please send at once for I want to keep right on with the Compound until the chickens are well.

Yours very respectfully,

Mrs. Annie Miller.

Button Wrllow, Colo.-My Dear Mrs. Johnson: Your nice letter and valuable book received. I did enjoy your nice letter so much and thank you for your interest. I know you have wondered at my delay. Enclosed please find the money order for the book. Thanking you for your favors, I am

\section{Your friend,}

Mrs. William Tracy.

Center Polnt, Iowa, Nov. 15, 1905.-My Dear Mrs. Johnson: Your Compound is all right and I want you to send me fifty cents worth by return mail. My chickens are getting all right and they are commencing to lay, all from the sample you sent me.

Yours respectfully,

Zona HaINeS.

Woodward, Iowa, Oct. 5, 1905.-Mrs. D. C. Johnson, Dear Friend: I am so thankful for your book and your instructions. I never found anything that did me so much good in regard to poultry raising. I found your Compound to be just what we need to raise chicks. I had a flock of seventy chicks that were dying at the rate of four and five a day. I gave your Compound according to directions and only lost two after that. I would not try to raise chickens without it. I wish I could tell every one that has trouble in raising chickens about it.

From your friend,

Mrs. Lewrs Johnson, 


\section{Things to Remember}

The mongrel is a thing of the past in profitable poultry culture.

It is the little things well looked after in the poultry business that assures success.

The eager, active, hungry hen is the profit maker. Lazy chickens, like lazy people, are worthless.

Things should not be done by halves in the poultry business. If it is right, do it right; if it is wrong, leave it undone.

The world is full of hopeless failures which could have been successes had they devoted to real work one-half the energy devoted to complaining.

If you have poor incubators, poor brooders and poor instructions, I would advise you to let the poultry business alone, for failure is sure to be the result.

Do not buy poor musty grain just because you can get it cheap. It lacks nutriment and often causes sickness in your flock, especially among the young chicks.

If you start in the poultry business and make a failure of it do not give up in dispair, but find the cause and remove it if possible. Others have succeeded, so can you.

For a cold there is nothing better than a little kerosene in the water you give your fowls. It removes the secretions in the head and removes the phlegm in their throat.

Lice multiply with wonderful rapidity, and unless checked, a hundred will soon grow to a million. Conquer these before they get well started, if you would avoid ruin to your poultry prospects.

The common life of every day, with its cares, necessities, and duties, afford ample opportunity for acquiring experience of the best kind and its most beaten paths provide the most true worker with abundant scope for effort and room for self improvement. 


\title{
Poultry Culture, Incubators, Brooders
}

\author{
Their Advantages on the Farm and \\ the Profit Derived Therefrom $* *$
}

\author{
Paper Read By Mrs. Rebecca Fohnson, at the Farmers' Institute, Maxzell, \\ Wednesdav, Fanuary 25, 1905.
}

T Do not know that I can explain poultry culture, incubators, brooders 1 and their advantages on the farm and the profits derived therefrom as well as those who have more literary ability, although $I$ have made these a study for over twenty years. However, I will try to explain it to you to the best of my ability.

The people that are making money in this progressive age are those who have the foresight to use the most improved facilities; those who fail are those who neglect their opportunities. Success in any branch of agriculture seems to depend upon the effort that one makes to utilize the most modern machinery and methods.

The hen is a very good hatching machine, but very slow. Very few people who depend upon the hen for hatching are able to make a commercial success of poultry; it is like making butter from a large herd of well fed cows, with the old fashioned up and down churn, or dropping corn by hand and covering it with a hoe, and then cultivating it with one horse and a single shovel plow as our fathers used to do. 'Tis true they made good butter, and raised good corn in those days, but could a man make a livelihood for a large family raising corn in that way today? No, we must have labor saving machinery, hence the incubator and brooder. They are the poultryman's labor saving machines; they enable him to do business on a large enough scale to make money, besides a living, and this is not all; eggs command a good price and are ready sale for cash, all the year around, consequently, we cannot afford to let old Biddy waste her time and energy setting and raising a brood when we can do it just as well for her, while she is laying the golden egg that fills our incubators, pays our store bills, and furnishes a nice boiled or fried egg for breakfast. No experienced poultryman at the present time will undertake to rear fowls in large numbers for the production of eggs and depend on the hen that lays the egg for incubation, because those Mediterranean breeds, or non-setters as they are usually called, such as the Leghorn and Minorcas cannot be depended upon for natural incubation, consequently, artificial incubation must be resorted to if we would make poultry culture for egg producing a success. Leg- 
horns and Minorcas nèver become broody the first year, and seldom the second. They do not make good incubators because they are too nervous. If you go near the nests where they are setting they will fly off like "a shot out of a gun," and often break their eggs. I set every hen that became broody last summer on duck eggs, and then did not have enough, so I thought I would force some to set, but they set standing every time, hence, you see, if I had not resorted to artificial incubation to hatch my chicks. I would have (excuse slang, please) "come out of the little end of the horn," and missed all those nice fried chickens, $\$ 250$ and 500 pullets that are paying for our living today. 'Tis true some do not have success with incubators, but there are so many different makes of machines on the market today, and as they are all the best, so the companies that make them claim, you see it would be very hard for a person having little or no practical knowledge of the natural laws of incubation and what mechanism is required to constitute a good machine, to distinguish the difference be. tween a good and a poor machine.

For best results an incubator must have a good heating device; one that will distribute a uniform heat throughout the egg chamber. There should be ventilators in the bottom, ends and top, and the operator should have good instructions telling how and when to use these ventilators. The cause of chicks dying in the shell is the lack of oxygen in the egg chamber at pipping time.

It is just as essential to have a good brooder as it is to have good in. cubators; if you try to get along without one I would advise you to try to get along without the other, and you should have at least two brooders to one incubator. There is where I have made a mistake, to my sorrowcrowding too many chicks in one brooder. It will cost a little more at the start, but it will pay big dividends in the end.

Keep the temperature at ninety the first week, and as the chicks grow older and stronger, gradually lower the temperature and in a little while they can do without artificial heat altogether. We made a large brooder ourselves, which is comparatively inexpensive, to put our chicks in after they are three or four weeks old. They are too young to wean from a brooder at that age, and it keeps them safe from vermin that usually infest the poultry yards The little chicks become very much attached to their brooder and rely upon it for shelter and protection just as much as they would a hen. Do not feed brooder chicks anything but grit for thirty,six hours after hatching, and I would advise you to take a dose or two yourself, for you may need a little grit to help you through trying difficulties that are sure to arise at the end of eight days if you overfeed your chicks. In raising brooder chicks always keep in mind that "cleanliness is next to Godliness," for you cannot raise chicks where lice, mites and filth exist. 
Poultry raising appeals strongly to most people because of its adaptability as a combination with farming. In fact, poultry keeping demands the carrying on of some other lines of work inorder to make the most profit possible from one's labor. The poultry business requires no great amount of capital, and considerable poultry can be kept largely upon what would otherwise be a waste; there is much waste about a farm that cannot be utilized in any other way as effectively as by poultry, which pick up the last grain, whether in the manger or in the refuse and convert it into profit. Waste in the feed yard is also converted into profit; there is nothing that will glean after hogs but poultry. Then when the grain is threshed the straw pile will furnish a great deal of picking for them, even with the best kind of threshing. In the fall there are small potatoes, cabbages, turnips, squashes, onions, carrots and beets that are not marketable; poultry like them and will eat them with a relish. In fact. there is nothing to take the place of poultry for converting the waste materials on a farm in to marketable products. There is no longer any question but that poultry is profitable, even when kept alone, but much more-so when the business can be combined with other branches of farm work so that each department fits into the other, and the waste of one is utilized by the other. Poultry keeping can be engaged in as a side line with almost any business which will allow one time enough to give it careful attention each morning and evening.' Many business men are doing well with small flocks under conditions that could hardly be termed favorable, but the hen will give a good account of herself under almost any kind of a combination if she is given reasonable care. On so many farms you will find the poultry badly neglected. The women are generally expected to look after them, and if they are not very strong and are doing their housework without any help, you will find the hen house full of lice, mites and filth, not a fit habitation for any living creature; Husbands, here is where you can lend a helping hand and utilize your time on rainy days. Clean out, whitewash, renovate and fumigate the hen house, and your wife will be perfectly willing to do the rest. It is not necessary to build a castle for chickens, but it is necessary that the house should be warm, roomy and properly lighted, and keep in mind that old adage; it applies to hen houses as well as brooders and colony houses.

I have heard a great many persons express the desire to get onto a small farm where they can make a comfortable living without having to work too hard, and at the same time live an independent life. Poultry offers one of the very best leaders for such a place and it pays as much money for the labor and money invested as any kind of business one can engage in. On a place of this kind one is able to be at home with one's family, and places of this sort offer the best possible conditions for the rearing of children. Such a home will always be looked upon with memoe 
ries that grow dearer as the years come and go. The diversity of life on a small farm of this kind has a tendency to keep up the interest and make the work more attractive and less irksome to the children than where one line is followed exclusively.

During the year 1899 the hens in the United States deposited 1,293,818, 144 dozen eggs. Now a case of eggs contains thirty dozen, hence it would require 43,127,272 cases to hold the annual output. Comparatively few people know or realize that the hen produces more wealth every year than all the gold and silver mines in the world. The value of the poultry and egg product in the United States in 1890 was greater than that of either gold or silver produced in the entire world during any previous year since the record began in 1493 . The poultry and egg products of 1899 exceeded in value the pig iron by more than $\$ 21,000,000$ and the eggs alone were valued at $\$ 144,286,370$

In 1899 all the wool product in the United States amounted to but $\$ 45,723,793$, while the value of the poultry and eggs amounted to the vast sum of $\$ 281,178,247$. You see the value of wool is less than sixteen per cent that of the hen product Isn't it about time for the farmers to begin to study the relative market value of the hen to their other products? The eggs and poultry sold by the people of the United States in 1899 was greater than the value of all animals slaughtered, and was far more than the entire oat crop. Would you believe that the hen produced more cash than the entire wheat crop of twenty-eight states and territories, including Illinois, Iowa, Pennsylvania, Missouri, New Jersey, Texas and Wisconsin? It's a fact. She produced a greater value than the corn crop of eighteen states and territories, including California, Colorado, Massachusetts, New York, North Dakota, Washington, Oregon and Wyoming. The value of all the poultry in the United States reserved for breeding and laying in 1900 was fixed by competent authority at $\$ 70,000.000$; the number of fowls at $250,681,598$, yet from this number of fowls valued at $\$ 70,000.000$ was produced for the market, eggs valued at $\$ 144,289.370$, and poultry worth $\$ 136,891.877$ a grand total of $\$ 281,178,247$, or over 400 per cent on the investment. Can you beat such a record by engaging in any other legitimate business known to commerce?

Please keep in mind that the above figures apply only to poultry and eggs produced on farms. The vast amount produced in villages of the country added to the above makes the totals more staggering, besides the many millions slaughtered for table use throughout the country, which is not considered in the above report, would bring the real value of the poultry product up to an overwhelming amount. Now isn't it about time for the farmer to give more serious consideration to the patriotic old hen, when it is the most profitable, healthy and enjoyable occupation un. der the sun. 
But my friends, let me say a few words to those of you who contemplate poultry culture for a livelihood: You must have love for the work, and an ambition to do that work, and by persistent effort and investigation you will acquire knowledge, and after getting practical experience, then persevere and you will overcome difficulties. and success will be the result. If you will only start right and stick to it I promise you good returns, not only in cash, but in health, strength and all that goes to make life worth living.

I could go on at length pointing out its fascinations, pleasures and advantages, but time forbids, but will say to the new beginner; I am with you in spirit, sympathizing with you in your time of trouble and rejoicing with you in your success. I am ever your friend and well wisher. 


\section{N D E X}

Breeders and Success................................ 35

Bill for Closed Feed Yard............................. 39

Brooder for the Chicks, How to Prepare ................... 14

Culture of Geese.................................. 24

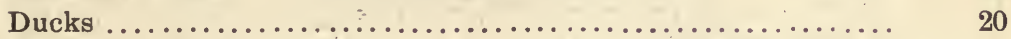

Diseases and Their Remedies......................... 41

Apoplexy ..................................... 44

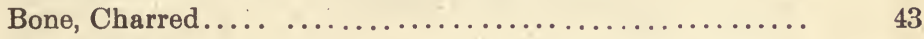

Bath, Dust................................ 43

Crop Bound................................ 47

Cholera ...................................... 47

Diarrhoea, How to Treat It ..................... 44

Dysentery in Chicks, Cure for.................... $\quad 42$

Fowls, Over-fat ................................ 43

Poultry, Good Tonic for........................ 43

Grit for................................ 43

Roup, Cure for............................. 48

Scaly Legs, Cure for......................... 47

Early Hatched Chickens are Best...................... 19

Find a Good Market and Meet Its Demands................. 32

Feeding Hens for Egg Production in Winter................ 28

Feed Yard, Bill for ................................ 39

Grow Speltz for Your Poultry ........................ 35

Geese, Culture of ................................ 24

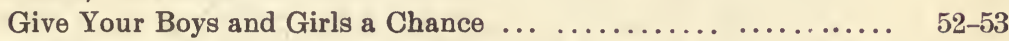

How to Prevent Chicks From Dying.................... 11

How and What to Feed Brooder Chicks................... 17

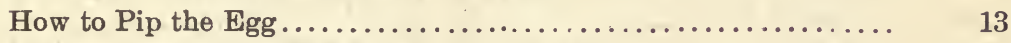

How to Prepare the Brooder for the Chicks................. 14

How to Hatch Ducks by Incubation...................... 20

How and What to Feed Ducks........................ 21

How to Start Your Incubators....................... 7

How to Prepare Young Cockerels for Market................ 32

How to Build a Cheap Poultry House................... 37

Introductory........................................ 3

Leghorns Not Good Setters........................... 35

Mrs. Johnson's Poultry Compound..................... 41

Directions for Preparing ...................... 41

Directions for Using $. . . \ldots \ldots \ldots \ldots \ldots \ldots \ldots \ldots \ldots \ldots \ldots, \quad 42$ 
Mrs. Johnson's Method of Forcing a Molt................. 29

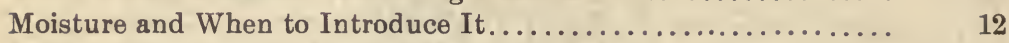

Mating, Breeding and Rearing Turkeys................... ${ }_{22}$

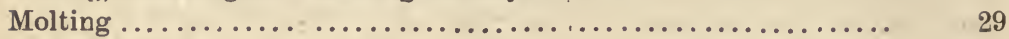

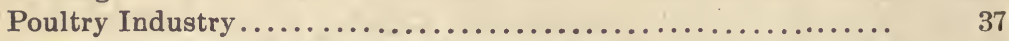

Proper Temperature for Successful Incubation............... 8

Poultry Culture, Incubators, Brooders................... 58-61

Poultry Hints.................................. $49-51$

Poultry House................................. 37

Recipe for Keeping Eggs.......................... ${ }^{36}$

Removing Chicks to the Brooder....................... 15

Saving Eggs for Incubation........................... 5

Testing the Eggs to Set............................... 6

Testing Eggs for Fertility ............................ 6

Turning and Cooling the Egg $\ldots \ldots \ldots \ldots \ldots \ldots \ldots \ldots \ldots \ldots \ldots . \ldots \ldots \ldots \ldots$

The White of the Egg Makes the Chick................... 31

Talk on Incubators and Brooders....................... 36

Turkeys..................................... 22

Testimonial Letters to Mrs. Rebecca Johnson.............. 54-56

Things to Remember.............................. 57

Ventilation and How to Prevent Chicks From Dying in the Shell. 11

When to Remove Chicks to the Brooder................... 15

Which is the Best General Purpose Fowl?................. 28

Young Cockerels ................................ 32

\section{INDEX TO ILLUSTRATIONS}

Portrait of Mrs. Johnson ......................... Frontispiece

Buff Coching....................................... 38

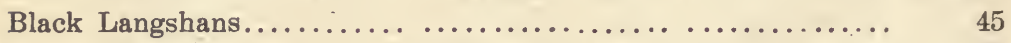

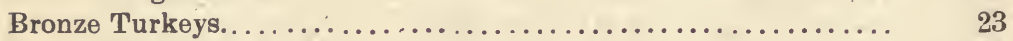

Barred Plymouth Rocks.............................. $\quad 26$

Feed Yard and Brooders,............................. 41

Light Brahmas.................................... 46

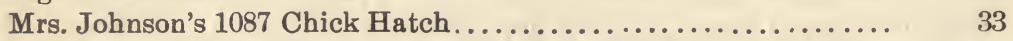

Mrs. Johnson and Little Daughters and Their Ducks........... 52

Mammoth Imperial Pekin Ducks....................... 21

Rose Comb Brown Leghorns.......................... 34

Silver Laced Wyandottes .......................... 27

Single Comb Brown Leghorns......................... 33

Toulouse Geese.................................. $\quad 25$ 


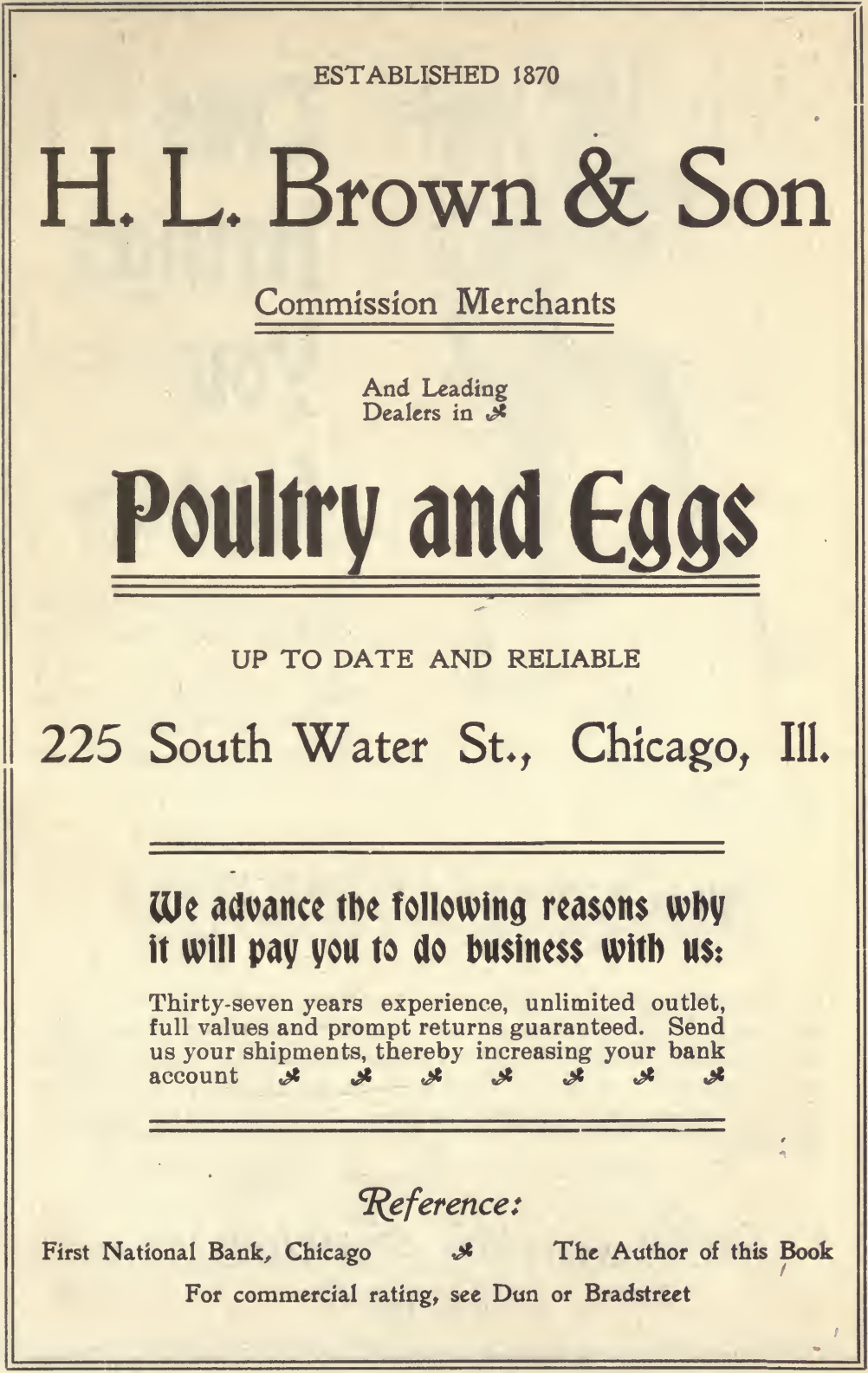



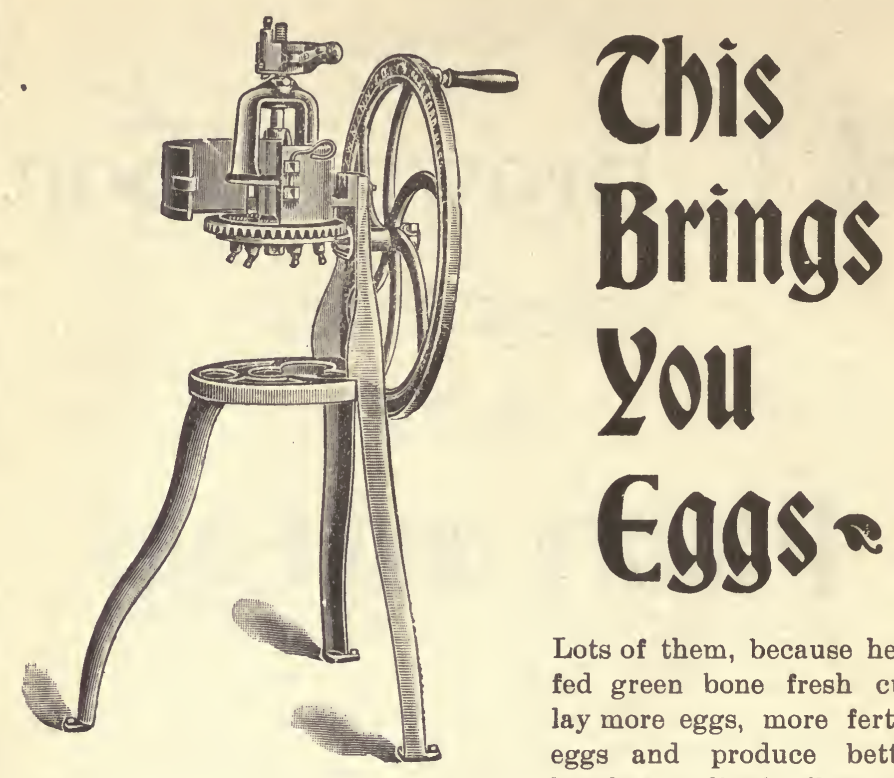

Lots of them, because hens fed green bone fresh cut, lay more eggs, more fertile eggs and produce better hatches, earlier broilers and heavier market birds. It gives the hen the protein and other egg elements she needs to keep up her work. If you feed green cut bone, you'll need a *

\section{MANN'S LATEST MODEL}

The one that cuts all the bone, meat and adhering gristle, clean, fast and fine. Mann's has open hopper, specially tempered knives and self-adjusting automatic feed that adapts the eutting to the strength of the operator. It never clogs and leaves no uncut slivers nor chunks. Mann's is Sold on Ten Days Free Trial. No money in advance.

Write for free illustrated catalog.

\section{F. W. Mann Co., Milford, Mass.}

\section{Box 192}




\section{Payne's Alfalfa Feeds}

TO GET THE BEST RESULTS YOU

MUST USE THE VERY BEST FEED

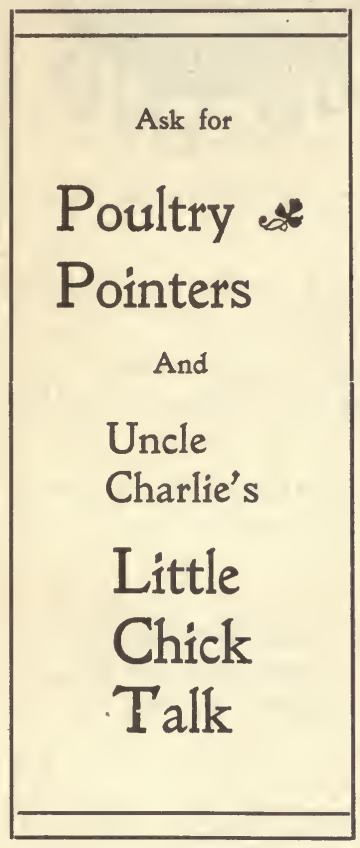

\section{Alfalfa Feeds}

PAYNE'S PURE ALFALFA MEAL

PAYNE'S POULTRY MASH

Grain Feeds

PAYNE'S CHICK FEED

PAYNE'S HEN FEED *

ALFALMO No. 33. ALFALMO SWINE FEED For Fattening Cattle For Hogs

\section{ALFALFA MEAL CO. Omaha, Neb.}




\section{Poultry

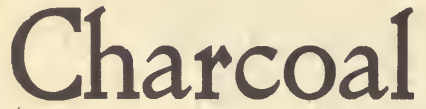

is the greatest

Natural Ton ic

and Invigorator

ever produced $*$

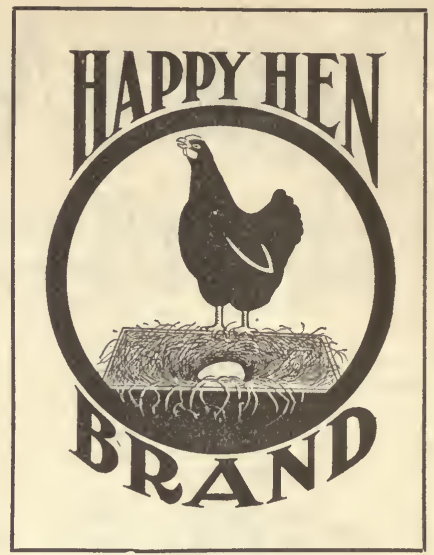

It is made from hard wood, thoroughly burned, then crushed, screened, and put up in twenty-five-pound sacks.

We make it in three sizes-No. 1, Course, for large fowls; No. 2, Medium, for growing birds, and No.3, Fine, for young chicks and for mixing in soft feed.

Every bird needs a quantity of Charcoal to keep it in the best of condition, therefore it will pay you to lay in a stock and keep it constantly before yours.

No. I Size...................\$1.75 per $100 \mathrm{lbs}$.

No. 2 Size $\ldots \ldots \ldots \ldots \ldots \ldots \ldots \ldots \ldots 1.75$ per 100 lbs.

No. 3 Size ...................\$2.00 per $100 \mathrm{lbs}$.

F. 0. B. Pittsburg

Send for our circular of dependable Poultry Supplies, and let us quote you interesting prices on anything you may want.

$+\infty x+\infty$

\section{STAPLER POULTRY SUPPLY COMPANY}

\section{Arrott Power Building PITTSBURG, PA.}

I can recommend this charcoal as the best I have ever used-THE AUTHOR. 





\section{Mrs. D. C. Johnson's Brooders \& Incubators}

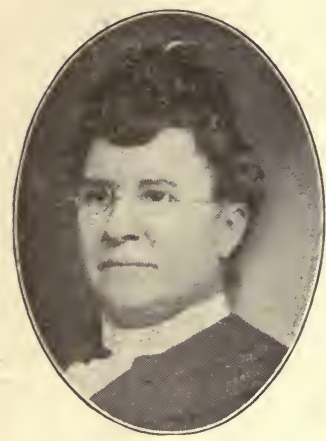

Mrs. D. C. Johnson

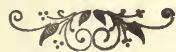

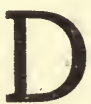

EAR READERS, I have shown by actual demonstration (as you will see by the cuts in this pamphlet) what is possible for persons to do with my incubators and brooders. Also my compound, and book on "How to Hatch, Brood, Feed and Prevent Chicks From Dying in the Shell," a long title, but one that covers the question of success. I had this book published after twenty-five years of practical experience with incubators and raising brooder chicks. I made my first incubator from two dry goods boxes with my own hands. I took lessonsfrom a hen by placing a thermometer under her, and watching her movements closely and thus learned the natural laws of incubation from nature. The result of my first hatch was 108 chicks from 116 eggs. I had never seen an incubator; did not know the mechanism that was required to construct a hatching machine, but I found that every thing is learned by persistent effort and investigation. I have experimented all these years, making improvements in my incubators and brooders and also my method of operating them, until I have, I think, the best equipments for hatching and brooding little chicks, also the best instructions that were ever placed upon the market; at least I demonstrated the fact. When I advertised, just after my first test, and two weeks before the hatch was due, that I would hatch 2,000 chicks in one day and exceeded my promise by 330 , for by actual count I hatched 2,330 chicks, only loosing 140 eggs of those left in my incubators after my final test. In 1905 I hatched 1,087 chicks in one day, only loosing 23 eggs. I 
give with each machine one of my books, 50 eents worth of compound-enough to make one gallon of medicine, and last, but not least, an electric danger alarm that will ring when the thermometer registers the danger point. This alarm was invented and patented by myself, and is one of the greatest improvements on incubators for many years. One can go to bed and sleep the sleep of the just. Your bell will tell you when there is danger, will fit any machine. My compound is sure cure for roup and bowel trouble in little chicks (read the testimonials), a 50 cent package will make one gallon of medicine, a whole summer's treatment. To try its merit send two cents and receive a trial package free. I sell my book for $\$ 1.00$. To those already having incubators it will be a wonderful help, to those that have had very little practical experiece in the art of artificial incubation. I guarantee my lice powder to rid your place of lice and mites if used according to directions, or money refunded. A great many people that will receive this little pamphlet have already heard of me, as so many papers all over the country have published an article telling of my wonderful success in hatehing and raising poultry, so you need not be afraid to trust me for I am just who and what I pretend to be.

My incubators are hot water incubators, I have found that hot air machines demand too much attention, the temperature runs up too quick also down too quick, especially at the last of the hatch. This is the critical time as there is so much animal heat in the eggs. There should be plenty of ventilation in an incubator so there will be evaporation in the egg which is absolutely necessary so that the chicks will have room to take on its form, pip the shell, turn clear around and come out. If a chick takes up too much albumen, or the white of the egg, (and it is sure to, if the incubator is not properly ventilated), it will grow so large and pack in the shell so tight it can not move and you know the result. If you purchase an outfit of me I can help you in the way of advice which would be worth a great deal to the new beginner. I will make a special price on several incubators and brooders if ordered at one time. 
Dear readers, I solicit a share of your patronage at least. .Wishing you success I am ever your friend,

\section{MRS. D. C. JOHNSON, Maxwell, Iowa.}

\section{A WORD ABOUT OUR BROODERS}

We do not hesitate to say that our brooders have no equal, and this statement is based entirely upon a comparison of results obtained. We heat our brooders with hot air. We make some with pipes over head and some with drums underneath. Our brooders have two sections, a brooder with house and a feed room or brooder attachment. We used to build the feed room and brooder separate, but now combine the two, saving expense and labor for the operator. The house is warmer than the feed room, this affords them-a choice of temperature. Both rooms are warm enough at all times to keep the brood comfortable without crowding and trampling each other. Brooders without a feed room are not a success, for chicks must have exercise and a change of temperature. The food also becomes soiled if fed in a brooder and chicks kept in a brooder any length of time without the feed room will contract disease. I use out door brooders without a brooder house. I could not raise chicks in such great numbers if I had to have houses for each brood. It would be too expensive and too much labor, for not only would the brooder have to be kept clean, but the brooder house also. I have from 20 to 30 of these brooders on my farm all the time, besides I have a great many brooder houses where I put my chicks after they are weaned from the brooder. If a person should want several brooders I will make a special price that will surprise you.

The ventilation system is perfect in our brooders, affording the chicks a constant supply of pure fresh air that has been warmed at the top of the brooder before reaching them. The floor of the brooder is 4 inches above the ground which insures freedom from dampness and vermin. We ship our brooders complete with all necessary fixtures. 


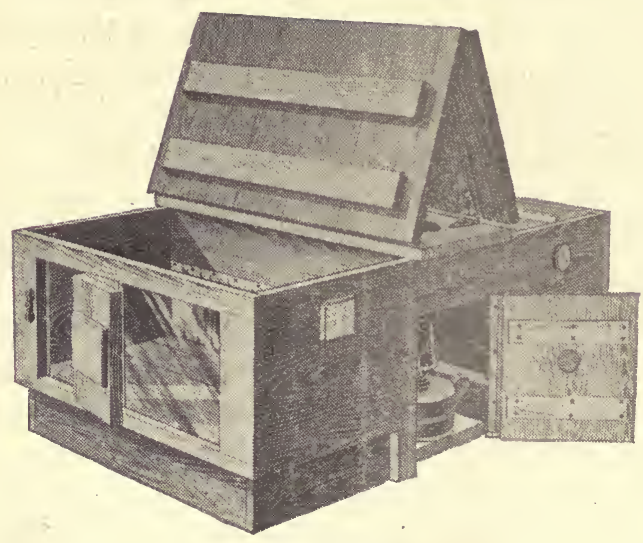

No. 1 Brooder

MRS. JOHNSON'S NO. 1 INDOOR 100 CHICK BROODER, PRICE \$7.50, SHIPPING WEIGHT 85 POUNDS

In all features this 100 chick brooder is exactly like our No. 2 indoor brooder, excepting capacity. All parts of the boxes are uniformly heated. If you will notice our lamps are in the side instead of the end; this is a great saving of oil as there is no heat wasted, as is the case when the lamp is at the one end of the brooder. 


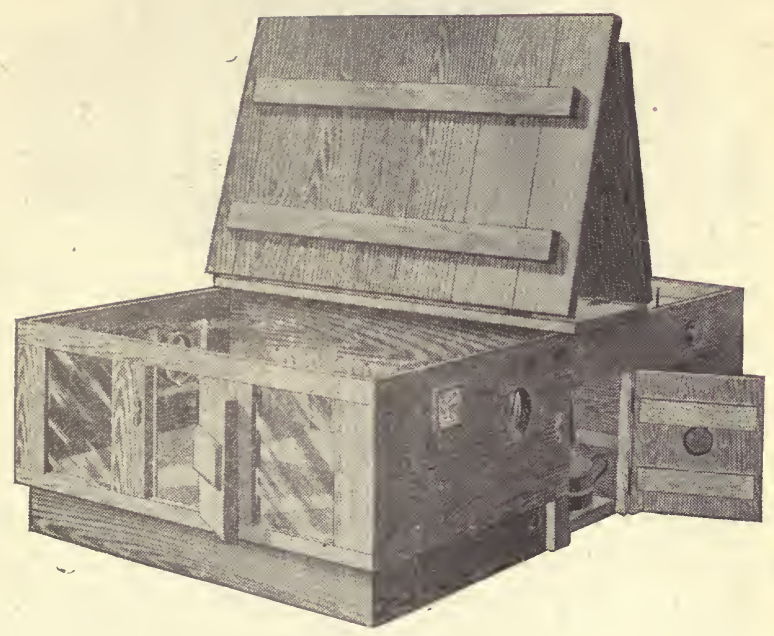

No. 2 Brooder

IMRS. JOHNSON'S NO. 2 INDOOR BROODER 200 CHICK CAPACITY, PRICE \$8.50, SHIPPING WEIGHT 90 POUNDS

Our No. 2 brooders have the feed room attachment and the floor is 4 inches from the ground, preventing dampness and vermin. Floor space is $50 \times 32$, the houses measuring $37 \times 30$ and the feed room $30 \times 20$. Like all our machines this No. 2 is shiped all complete. 


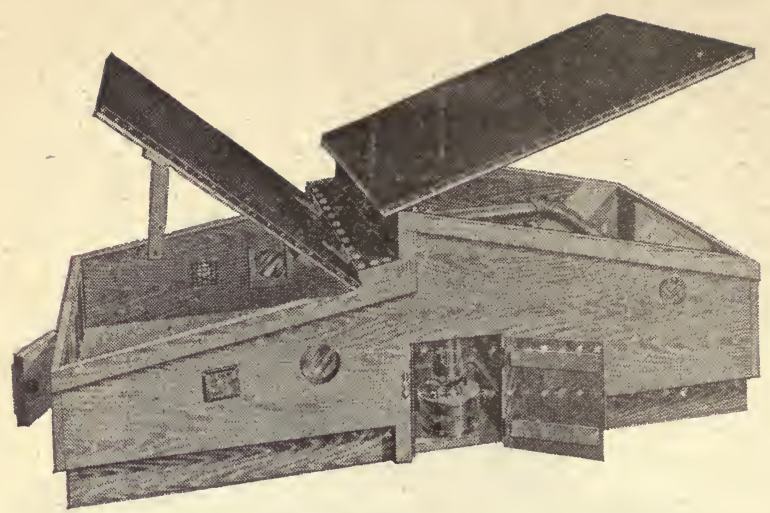

No. 3 Brooder

\section{IMRS. JOHNSON'S NO. 3 OUTDOOR 200 CHICK CAPACITY, PRİCE $\$ 10.50$}

This brooder has no equal. It takes the place of brooder and brooder house. Has feed room attachment. It measures $54 \times 33$ inches, the floor space of the house is $27 \times 31$, the feed room is $24 \times 31$. We ship No. 3 all complete. I regret that I haven't cuts to show all of our brooders.

\section{NO. 4 BROODER}

I did not get a cut of my No. 4 and No. 5 brooders in time that I could put it in this pamphlet. Our No. 4 is a 200 ehick brooder and is heated with a drum in the center and the lamp is placed directly under this drum. I am having only the one size of this kind of brooder made, it is equipped with the feed room just the same as our other brooders. This brooder ean not be excelled by any thing ever placed upon the market for early spring, or in cold weather. Price $\$ 12.50$; it is 6 feet long and 3 feet wide; it answers for brooder and brooder house.

\section{NO. 5 BROODER}

Our No. 5100 chick brooder is the best little brooder ever sold for the money. It is an out door brooder, has a feed room 
attachment and we are selling this brooder for the small sum of $\$ 6.50$. We have never offered this brooder for this exceptionally low price before, but we want our patrons to have good success in raising their chicks, and a person can get.two of the No. 5100 chick brooder, for nearly the same money as they would have to pay for a 200 chick brooder. I do not know that I will get my euts in time to put in this pamphlet, but will send it later on by request. The cause of such a great fatality among brooder chicks is crowding too many chicks in one brooder. Take advantage of this offer and raise most all the chicks you hatch. If you take two or more brooders I will make the price still better. Write for special prices and cut of this brooder.

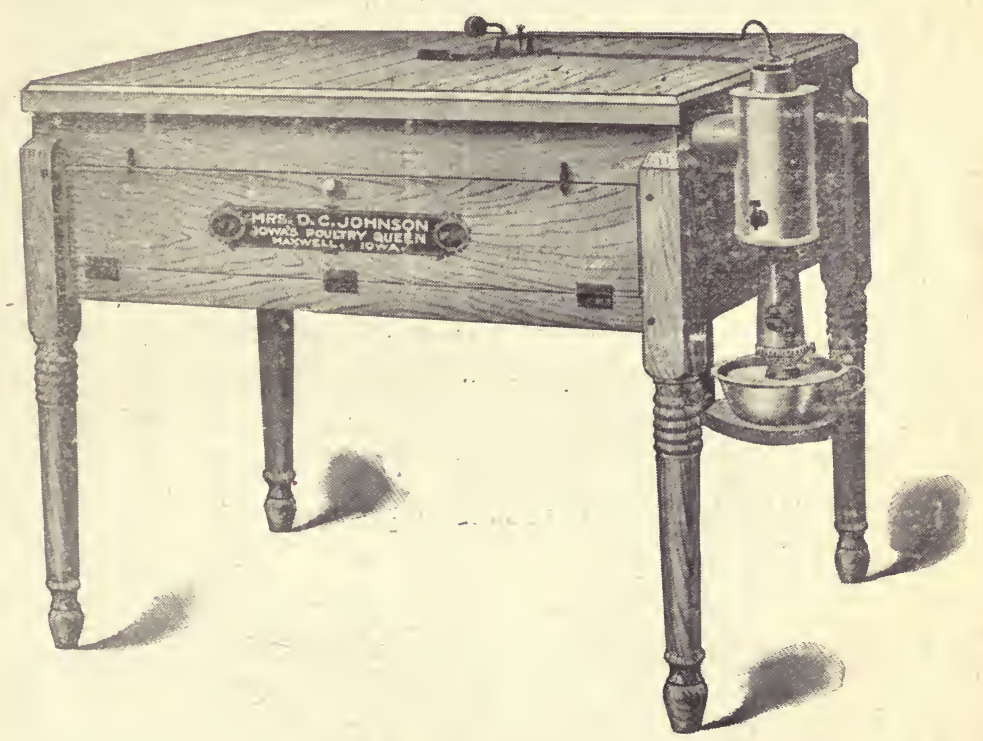

OUR NO. 3 INCUBATOR

We always urge our friends to buy our No. 3, $240 \mathrm{egg}$ incubator because it costs less in proportion to its size. It does not take any more time or oil to operate it than do the smaller 
machines then you have more to show for your three weeks' work, if one does not want so many chicks as a 240 incubator will hatch they could sell a part of them to defray expenses for oil and eggs. It costs the manufacturer almost as much to construct a small machine as it does a large one hence you see there can not be very much difference in the price. Prices are as follows :

No. $1-60$ egg capacity.............. \$9.75

No. 2-120 egg capacity............. 15.50

No. 3-240 egg capacity............. 18.00

I have made a little change in my incubators since I had the above cut made. How I come to do it. Last year when I made the "big hatch," the doors to one of my incubators was broken off, so I just operated it with the glass door only. It was easier to operate for I did not have to open the door I would just look in through the glass. I had just as good hatch from this incubator as I had from any of the rest, consequently I left off the out side door and made a double glass door. The incubator is so much easier cleaned with the one door than with two and one will obtain just as good results. I improve my machines in every way I can to lessen the labor for the operator. Always fill the tank with hot water, soft if it can be obtained. In early spring the living room, bed room or kitchen are the best location for the incubator, but in real warm weather the cellar is alright. Write me for particulars.

\section{Write me for prices on all breeds of poultry.}




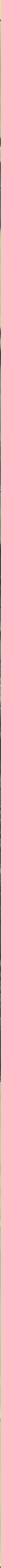




\section{Testimonial Letters to Mrs. Johnson}

\section{FROM THE GOVERNOR OF IOWA}

Executive Office, Des Moines, August 20, 1906.

My Dear Sir: . I beg to acknowledge your very inceresting letter of the 17 th instant. It always gives me great pleasure to mark the progress of Iowa in any direction, but I find especial gratification in what you say with respect to Mrs. Johnson. The world is not very kind in a business way, and she can well feel proud of her victories over adverse aircumstances. She well deserves the title "Poultry Queen of Iowa." Yours · very truly, Iowa State Register and Farmer, City. ALBERT B. CUMMINS.

Iowa City, Iowa, April 15, 1906.

Mrs. D. C. Johnson, Maxwell, Iowa.--Dear Madam: By inquiry, I am referred to you by Prof. W. J. Rutherford, Iowa State Agriculture College, for information on poultry. I desire poultry for market, and from what knowledge I have, have thought of securing prolific layers as a breed. Also I wish to purchase one or more incubators and am satisfied of several good ones on the market, also some inferior ones, but for one unexperienced it is hard to decide; thinking perhaps that information from one who has had experience along this line would probably evade many mistakes more costly than information secured at begining. Hoping you can furnish me information desired, I await your terms, etc.-Yours very respectfully, R. S. COCHRAN,

Jackson, Minn., July 10, 1906.

Mrs. D. C. Johnson, Maxwell, Iowa.-Dear Madam: Your book on poultry raising and how to operate incubators has been recommended to me. Please send me one by return mail and oblige. Enclosed find P. O. order for $\$ 1.00$ for same.-Yours truly, GEO. D. HORST.

\section{Slater, Iowa, May 6, 1906.}

Dear Mrs. Johnson: Enclosed find check for three dollars (\$3.00) for which please send me your Poultry Compound at agent's prices, as I want to see if I can do something with it. It is rather late in the season to do much this year, but perhaps I can sell enough so l can do better next year. I have had several inquiries for it, and I thought if I had some on hand there would be still more demand for it. I may try the other remedy later on. When people find how good your compound is I think they will be very apt to call for the other. Hoping you may be able to send it at once, as I have two or three sales in view now, I remain yours very truly, MRS. J. M. ERICHSON.

Kalona, Iowa, June 1, 1906.

Mrs. Johnson-Dear Friend: No doubt you think me a fake, as I have not returned the money for your compound, but I think of you every time I look at my nice flock of chicks. I sold the compound. We 
all know it's all right. All who have used it feel so thankfnl that they have found something to save their little chicks.

I just took out the last of a hatch. I run the incubator as you say in your book. I got 100 chicks out of 127 eggs. I now have 350 , that will look small to you, but will set it again. I would like to raise enough to get one of your incubators. I tried your way of using moisture; it's all right. I took off 140 chicks the day I got your book and only lost four. Those got killed. Your name goes over the line every day by some one to some neighbor, praising your compound. I do wish I could sell some of your books. They all think it too much, but I den't. Now I send order for compound and will sell all I can for you, and I am paid for my trouble.-MRS. CORA LIEBIG.

P. S.-Will send for more compound and books if I can sell any. I remain as ever, a friend.- C. L.

\section{Parker, S. I)., July 19, 1906.}

Dear Mrs. Johnson-Please find enclosed one dollar money order for which send me some of your zonipount for my chickens as I believe it to be very good.-Yours truly, MRS. HOW WLL IYAVIS.

\section{Smithville, Mo., Marc'ı 27, 1906.}

Mrs. D. C. Johnson, Maxwell, Iowa-Well, Mrs. Johnson, I have beell waiting to see what success I would have from your book. I am well pleased with your instructions. I have hatched 115 chickens from 125 fertile eggs, and the chickens are a month old and are doing fine. I have to keep them in the house, as the weather is bad, but I have a room that I don't use and they seem to be doing well, and I have tried your medicine. I had a turkey that got sick and would not eat. I could not tell what was the matter with her, so I gave her some of your compound, as directed, and she is well and eats all right. I think it a good medicine.

Mrs. Johnson, did you ever try turkey eggs in an incubator, and how do they hatch, and do you have the White Holland turkeys? What do you sell the eggs at? I want to get a setting. The neighbors around here have been laughing at me about going by your instructions, but now they don't know what to think, as they are only getting about seventy and eighty out of the same size machines.-Respectfully yours, MRS. DAVID PARK.

Marcus, Iowa, July 7, 1906.

Mrs. D. C. Johnson-Dear Friend: I received your letter and Poultry Book, also the package of medicine; it did all that it claimed to do. Most of my little chicks got well. I hope you will forgive me for being so slow in sending you the price of your book, for which find $\$ 1.00$ money order. How much are your incubators and brooders?MRS. THOS. MEECHAN.

Emmetsburg, Iowa, June 10, 1906.

Mrs. Johnson-Dear Friend: Your Poultry Compound is all right, it is fine for wire cuts and sore shoulders on horses. Please send me fifty cents worth by mail. I don't know how much the postage will be, but if it is more than ten cents let me know. I suppose you have quite 
a lot of chicks this summer. Send the compound as soon as you can.MRS. M. H. GRACE.

Cape Sable Island, South Side, Nova Scotia.

My Dear Mrs. Johnson: When your book came I cried for joy, oh, I was so glad to get it, for it tells so many things that I never knew and it will be so helpful to me. Will be so glad when my incubator gets here, then I can help to keep the wolf from the door. My husband is a fisherman. Sometimes we have plenty then again the traps will be washed away, then we do not live so well. Eggs are such a good price all the year around we cannot help but do well after we once get a start. Now, my dear, you have the honor of placing the first incubator on the island. I am using your compound with good results. Enclosed please find $\$ 4.00$ for six packages of compound and one more bonk. Thanking you for your kind letters and advice, I am ever,-Your loving friend, MRS. JAMES C. PENNEY.

Lost Springs, Kans., June 16, 1906.

Mrs. Johnson, Maxwell, Iowa-I heard that your medicine was all right for sick chicks. Please send me one fifty cent package.-MRS. M. S. HERRING.

Fayette, Iowa, July 11, 1906.

Mrs. Johnson-I have just taken off an incubator full of chickens, and as I have always had trouble in raising them, I thought I would try your preparation, a lady was in here that knew of it, and recommended it so highly I was encouraged to write. Will you please write particulars. She could not remember what it was called, so I could do nothing until I heard from you. Wuuld like a reply as soon as possible.MRS. L. E. BURGET.

\section{Manhattan, Kans., July 8, 1906.}

Mrs. D. C. Johnson-Enclosed you will find stamps for which you will please send me trial package of Poultry Compound. I have tried to raise a good many chickens this summer and have not had very good success. Was informed that your Poultry Compound was very good and would like to try it:-MRS. ANNIE E. HOWENSTINE.

901 Kearney Street.

Lamoile, Iowa, July 9, 1906.

Mrs. D. C. Johnson, Maxwell, Iowa-Dear Madam: I saw your ad. in the Western Poultry Journal. Enclosed will find one dollar order for your book. We are running two incubators. I visited Mrs. Vader to see her chicks. She spoke about your book as a valuable aid to beginners. Please send to my address and oblige.-ISAAC H. PYLE.

Sioux City, Iowa, July 7, 1906.

Dear Mrs. Johnson-I will send $\$ 1.00$ by mail. Please send me two packages of Poultry Compound at once for I am out of it. It is the best stuff I ever gave to chicks. I am also giving it to my old hens. So please oblige me-MRS. HERMAN KLINGEBIEL.

Hinton, Iowa. 
Saffordville, Kans., July 12, 1906.

Mrs. Johnson-I have heard your medicine praised so much that I would like to try it if you will send us the free sample before we buy any.-Yours truly, FLORA KLATT.

Alexanderia, Va., August 14, 1906.

Mrs. D. C. Johnson, Maxwell, Iowa-Dear Madam: In answer to your letter of May 11, 1906, in which you also requested to "speak a good word" for you if I obtained satisfactory results, will say truthfully that the compound has worked wonders. I have tried many things, but this beats all. Mrs. Johnson, I would like to act as agent for this compound.- S. BOWLANGES.

Allerton, Iowa, January 20, 1907.

Mrs. D. C. Johnson-Kind Friend: I bought one incubator of you last year and set it three times and then sold it to one of my neighbors so I want to buy another one, will you give me prices. I think they are all right and I did fine with it last year and want to try again. Hoping to hear from you soon.-Your friend, MRS. O G. GIBBS.

Muscatine, Iowa,May 14, 1906.

Mrs. D. C. Johnson-Dear Friend: You sent us a trial package of your Poultry Compound and we know it has helped our sick chicks and we have not lost any of them. Since we gave them the compound and the book we got of you has been a great help to us, so piease send us one dollar's worth of your Poultry Compound.- Yours respectfully, MRS. FRED GROTH.

1161 New Hampshire.

Farley, Iowa ,January 23, 1907

Dear Friend Mrs. Johnson-Please find enclosed 50 cents in stamps for which send one package of your Poultry Compound. I do not want to be without it. I found out that it is good for a runaround that was very painful on a finger and it was thought that the nail would come off. The day I received your last package of compound I dissolved it ready for use. The finger hurt and bothered so, I thought any thing that did so much good as your compound would not kill if it did not cure. I held the finger into it its full strength, it gave it a dark color. I am glad to say that is all gone and the finger in a natural condition now. Since I wrote the 9th I have got more hens, I now have four hundred. I read with much interest your Life Story in the Northwestern Agriculturist. I thank you for the help your kind letters have been to me. As my circumstances are such that I must do all that I can to try to get back what is gone I pray for success that is if all for the best. -Yours sincerely, MRS. J. C. THOMPSON.

Ottosen, Iowa, May 15, 1906.

Mrs. D. C. Johnson-Dear Madam: I received incubator all right and have it going; it is satisfactory so far. Yes you sent me a book.Yours truly, MRS. P. G.'DAVIs'. 
Marcus, Iowa, January 19, 1907.

Mrs. D. C. Johnson-Dear Friend: I write you these few lines to inquire the price of 200 chick brooder, am thinking of getting one this spring. I have an incubator and brooder, but one brooder is not enough. Would you advise setting the incubator before the first of March? I was thinking of setting next month, but don't know whether or not, but will take your advice in the matter. What is the lowest price you will place incubators and brooders at? You wrote me last fall you would make prices for me in order to place one in this locality. Please write and let me know as soon as possible.-MRS. THOS. MEEHAM.

P. S. Last summer I put ventilators in incubators as you directed and hatched almost as many more chicks as I did in previous hatches. -MRS. T. M.

Nodaway, Missouri, May 12, 1906.

Dear Mrs. Johnson-The sample of your Poultry Compound received and used as directed for both old fowls and brooder chicks. The latter was what I wanted it especially for. I haven't lost one from bowel trouble since giving your compound and that is doing well for me for I always lose more or less every year and I think it is the best remedy for chicks. I will send 50 cents for a package and as soon as I can afford it will send for your book, which I know must be good. I used to live at Cambridge and it seems like writing back near our old town.-Yours truly, MRS. MYRTLE FICKLE.

Corydon, Iowa, May 16, 1906.

Mrs. Johnson-Dear Friend: I take the liberty to write you a few lines, I having heard of you through Mrs. O. G. Gibbs, a neighbor of mine. I like her incubator she bought of you so well and she seemed to have such good success with it that I have concluded to get me an incubator of some kind, would you please send me your summer prices on the 240 egg size and I will be very much obliged to you,-MRS. S. A. CARLSON.

\section{IOWA,S POULTRY QUEEN}

Mrs. D. C. Johnson, of Maxwell, Iowa, who last. year established the phenomenal record of over a thousand chicks at a single hatching, started out this season with the determination to break her own record. Some time ago announcement was made that on July 21st she would bring off a brood of 2,000 chicks.

Mrs. E. C. Nienaber, of Durant, who has been in correspondence with Mrs. Johnson and a close student of her methods, took occasion to go to Maxwell to witness this phenomenal hatch. Mrs. Nienaber says:

"July 21st was certainly an eventful day, not in Mrs. Johnson's life alone, but in the history of the art of artificial incubation.

In response to the advertisement in her home papers that on this day she would, at one hatching, take 2,000 chicks from the incubators, a large crowd assembled. But by actual count-in which the writer had a hand-she took 2,330 chicks from her incubators, leaving the small number of 140 unhatched. Mrs. Johnson's danger alarm was a wonder- 
ful help in this hatch for the weather was very warm and it was hard to keep the temperature under subjection.

One incubator which came under the writer's observation, hatched 136 chicks with only four eggs left in the incubator.

The event called together a large crowd of not only her admiring freinds, but a large number of curious and inquiring people, who were coming and going the entire day, many coming hundreds of miles. All felt amply repaid as it was a sight that will be witnessed but once in a life time.

An enclosure of perhaps $16 \times 20$ feet on the lawn was literally covered with the little wriggling, downy mortgage lifters.

How few who witnessed the sight realized the amount of labor and the tax on both brain and body. Mrs. Johnson has well earned for herself the title of 'Iowa's Poultry Queen,' or perhaps America's Poultry Queen or perhaps of the entire world.

Not only is she a successful amateur hatcher but she raises a larger per cent of what she hatches than ordinary poultry raisers. She certainly is an able person to give information on the poultry subject."

These words coming from such a reliable source and from olle so well known in Durant will give added strength to the testimony hitherto published concerning Mrs. Johnson's discoveries in artificial incubation and rearing incubator chicks.

Mrs. Nienaber was more than pleased with what she saw and learned during her visit with Mrs. Johnson and further declares that following the latter's methods has proven of inestimable value in this season's work.-Durant Star.

\section{MY COMPOUND IS GOOD FOR CALVES AND PIGS}

Neasho, Missouri, January 27, 1907.

Mrs. D. C. Johnson-Dear Madam: Enclosed pleased find 50 cents for some more of your compound. It is the best remedy for poultry I ever saw, and hope it will never be adulterated. Be sure and leave your formula with some one when you quit the business. Is it good for pigs and calves that have scours? We have between 4 and 5 dozen hens ,they are furnishing us with fully 2 dozen eggs per day; it is counting up in dollars pretty well. We get from 20 to 30 cents per dozen. I let a lady have some of your compound as her chickens had a bad case of roup. Thanking you for past favors, I am yours very respectfully, J. M. PROPST, Breeder of Thoroughbred Poland China hogs.

\section{A WÖB TÓ THE PUBLIC}

Now, my friends, there is no use for me to say more. These testimonials are self explanatory. If others can have good success with my Incubators, Brooders, Brooder Attachments, Book, Compound and Electric Alarm so can you. If you contemplate buying an Incubator and Brooder let me fit you out. If you already have an Incubator, my Book, Compound and Alarm would be wonderful help to you. Write me for particulars and you will greatly oblige

Your friend,

MRS. D. C. JOHNSON, MAXWELL. IOWA. 

